\title{
Can Parents' Value of Children's Happiness Predict Their Emotion Socialization and Parenting?
}

Tyia Wilson

Follow this and additional works at: https://researchrepository.wvu.edu/etd

\section{Recommended Citation}

Wilson, Tyia, "Can Parents' Value of Children's Happiness Predict Their Emotion Socialization and Parenting?" (2018). Graduate Theses, Dissertations, and Problem Reports. 8196.

https://researchrepository.wvu.edu/etd/8196

This Thesis is protected by copyright and/or related rights. It has been brought to you by the The Research Repository @ WVU with permission from the rights-holder(s). You are free to use this Thesis in any way that is permitted by the copyright and related rights legislation that applies to your use. For other uses you must obtain permission from the rights-holder(s) directly, unless additional rights are indicated by a Creative Commons license in the record and/ or on the work itself. This Thesis has been accepted for inclusion in WVU Graduate Theses, Dissertations, and Problem Reports collection by an authorized administrator of The Research Repository @ WVU. For more information, please contact researchrepository@mail.wvu.edu. 
Can Parents' Value of Children's Happiness Predict Their Emotion Socialization and Parenting?

Tyia Wilson, B.S.

Thesis submitted to the Eberly College of Arts and Sciences at West Virginia University

in partial fulfillment of the requirements for the degree of

Master of Science in

Psychology

Amy Gentzler, Ph.D., Chair

Aaron Metzger, Ph.D.

Amy Root, Ph.D.

Department of Psychology

Morgantown, West Virginia

2018

Keywords: adolescence, childhood, valuing happiness, parenting, emotion socialization, helicopter parenting

Copyright 2018 Tyia Wilson 


\begin{abstract}
Can Parents' Value of Children's Happiness Predict Their Emotion Socialization and Parenting? Tyia Wilson
\end{abstract}

Happiness is considered a priority for most people and understandably so due to its benefits. Happiness not only makes people feel good but leads to better health outcomes. However, emerging research found that valuing happiness at extreme levels can be detrimental to a person's well-being (Mauss, Tamir, Anderson, \& Savino, 2011). Yet, no research has directly examined if the concept of excessively valuing happiness can be applied to another person's happiness and in particular, one's children. Additionally, no research has examined how parents' beliefs about their children's happiness is linked to parenting behaviors and emotion socialization. Two present studies investigate whether parents' value of their children's happiness at extreme levels were associated with their emotion socialization and parenting behaviors. The first study focused on parents' positive affect socialization with mothers and children $(N=76)$ between 7 to 12 years old. The study found that valuing child's happiness at higher levels was associated with more parental socialization of savoring positive affect. However, mothers' value of their child's happiness was not associated with parental socialization of dampening, minimizing, encouraging, or reprimanding positive affect. The second study focused on parents' negative affect socialization beliefs and helicopter and indulgent parenting styles of both mothers and fathers with their adolescents $(N=116 ; 14$ to 18 -year-old). In Study 2, mothers and fathers who valued their child's happiness to a higher degree were more likely to believe they should reject their child's negative affect and were more uncertain on how to handle their child's expression of negative emotions. Mothers who reported higher levels of excessively valuing their child's happiness scored higher on indulgent parenting behaviors. However, 
excessively valuing child's happiness was not associated with parental emotion socialization beliefs of accepting or coaching their child's negative affect or helicopter parenting. Both studies contribute to the literature by applying research on excessively valuing happiness to parenting and provides novel insight into its association with emotion socialization. 


\section{TABLE OF CONTENTS}

I. Abstract (ppii-iii)

II. Introduction (pp1-13)

III. Study 1 Method (pp13-17)
a. Participants (pp13-14)
b. Procedure (pp14)
c. Measures (pp14-17)

IV. Study 1 Results (pp17-19)
a. Preliminary analyses (pp17)
b. Primary analyses (pp17-19)

V. Study 1 Discussion (pp19-22)

VI. Study 2 Introduction (pp22-23)

VII. Study 2 Method (pp23-26)
a. Participants (pp23)
b. Procedure (pp23-24)
c. Measures (pp24-26)

VIII. Study 2 Results (pp26-19)
a. Preliminary analyses (pp26-28)
b. Primary analyses (pp28-30)

IX. Study 2 Discussion (pp30-34)

X. General Discussion (pp34-40)

XI. References (pp41-47)

XII. Table 1: Demographics for Study 1 and Study 2 (pp48-49) 
XIII. Table 2: Study 1: Bivariate Correlation Statistics (pp50)

XIV. Table 3: Study 1: Hierarchical Regression Models Predicting Positive Affect (PA) Socialization from Mothers' Value of Children's Happiness and Covariates (pp51)

XV. Table 4: Study 1: Hierarchical Regression Models Predicting Positive Affect (PA) Socialization from Mothers' Value of Children's Happiness and Covariates (pp52)

XVI. Table 5: Bivariate Correlation Statistics for Study 2 (pp53)

XVII. Table 6: Study 2: Hierarchical Regression Models Predicting Negative Affect (NA) Socialization from Mother-reported Mothers' Value of Adolescent's Happiness (pp54)

XVIII. Table 7: Study 2: Hierarchical Regression Models Predicting Negative Affect (NA) Socialization from Father-reported Fathers' Value of Adolescent's Happiness (pp55)

XIX. Table 8: Study 2: Hierarchical Regression Models Predicting Parenting Behaviors from Adolescent-reported Parents' Value of Adolescent's Happiness (pp56)

XX. Figure 1a: Proposed model: Mothers' value of their child's happiness predicting use of positive emotion regulation behaviors with household income controlled (pp57)

XXI. Figure 1b: Trimmed model. Standardized estimates for the associations between mothers' value of their child's happiness and positive emotion socialization behaviors (pp58)

XXII. Figure 2a: Trimmed model. Standardized estimates for the associations between mothers' value of their child's happiness and positive emotion socialization behaviors (pp59)

XXIII. Figure 2b: Final model: Standardized estimates for the associations between mothers' value of their child's happiness, negative emotion socialization beliefs and parenting behaviors. (pp60)

XXIV. Figure 3a: Proposed model: Fathers' value of their child's happiness predicting negative emotion socialization beliefs and parenting behaviors (pp61) 
XXV. Figure 3b: Final model: Standardized estimates for the associations between fathers' value of their child's happiness, negative emotion socialization beliefs and parenting behaviors (pp62) 
Can Parents' Value of Children's Happiness Predict Their Emotion Socialization and

$$
\text { Parenting? }
$$

Generally, everyone wants to be happy. Researchers argue that being happy is essential for adaption and positive mental health (Diener, 1984). Happiness can lead to many beneficial outcomes, including a better quality of life and better health outcomes such as stronger immune system in response to infection (Cohen \& Pressman, 2006), healthier levels of heart rate variability (Bhattacharyya, Whitehead, Rakhit \& Steptoe, 2008) and overall lower mortality rates in people with higher levels of happiness (Chida \& Steptoe, 2008; Danner, Snowdon, \& Friesen, 2001). Research also shows that happiness is not only associated with better physical health outcomes, but mental and emotional outcomes as well. People who consider themselves happy report better self-control, self-regulation, coping abilities, and higher levels of goal attainment (Fredrickson \& Joiner, 2002; Sheldon \& Houser-Marko, 2001). Although there are many beneficial correlates and outcomes of feeling happy, valuing happiness at extreme levels (i.e., obsessing over being happy) can lead to negative outcomes for individuals (Gruber, Mauss, \& Tamir, 2011; Mauss et al., 2011). This study extends the limited research on valuing happiness by applying it to a parenting context and examining parents' excessive value of children's happiness and their parenting behaviors.

\section{Negatives of Extreme Value of Happiness}

There has been an extensive amount of research regarding the benefits of happiness but little research showing potential costs associated with happiness. Valuing happiness at extreme levels can be detrimental to a person's well--being. Mauss, Tamir, Anderson, and Savino (2011) conducted a correlational and experimental study to determine the role happiness plays on a person's well-being. The participants, who were all female $\left(M_{\text {age }}=37.6\right.$ years, $\left.S D=12.3\right)$ self- 
reported on the amount they valued happiness and their well-being. The researchers conceptualized excessively valuing happiness by a person's excessive or obsessive desire for happiness, endorsing such items as "Feeling happy is extremely important to me", "I am concerned with my happiness even when I feel happy" and "To have a meaningful life, I need to feel happy most of the time." Their results showed that the more the participants reported excessively valuing happiness, the higher their depressive symptoms and the lower their psychological well-being, life-satisfaction, and hedonic balance (i.e., joy and pleasure). The same results held true in the experimental study: participants who were experimentally manipulated to value happiness were less happy in a positive context (Mauss et al., 2011). Another study conducted by Mauss and colleagues (2012) examined the relationship between happiness and loneliness in two studies. Study 1 showed that the more people valued happiness, the more likely they were to report feeling lonely on a daily basis. Study 2 showed that inducing people to value happiness made them more likely to report greater loneliness (Mauss et al., 2012). Overall, this novel research suggested that valuing happiness at extreme levels can be maladaptive.

There are many reasons why excessively valuing happiness may backfire. Schooler, Ariely, and Loewenstein (2003) speculated three different reasons why pursuing happiness can be self-defeating. One reason why valuing happiness can be detrimental may be due to people not knowing what will truly bring them happiness. People often overestimate what will make them happy which sets them up for disappointment. Another reason pursuing happiness can be self-defeating is when a person's goal during an activity is achieving happiness rather than genuinely valuing the activity itself. The third reason valuing happiness can be self-defeating is that it may cause a person to constantly monitor whether they are happy which again limits the 
amount of attention and enjoyment on the activity itself (Schooler et al., 2003; Ford \& Mauss, 2014). Although there have only been a few studies that examines the detrimental effects of excessively valuing happiness, the results are consistent. Excessively valuing happiness is linked to higher levels of depression, loneliness, and lower levels of social well-being (Mauss et al., 2011; Mauss et al., 2012; Schooler et al., 2003). These same mechanisms could operate with parents' value of children's happiness. For example, parents who are excessively concerned with their children's happiness may have unrealistic expectations about how happy their child should be, and they may be overly vigilant about their child's emotional states and may intervene too often to prevent children's negative affect.

\section{Excessively Valuing Children's Happiness}

The need to be happy is not only a personal goal, it can trickle down to parents' goal for their child. Often times parents put their child's happiness before their own happiness, this is known as child-centrism (Ashton-James, Kushlev, \& Dunn, 2013). Child-centrism is popular in modern society and emphasizes the extent to which parents want their child to be happy, for example parents will sacrifice their own well-being for their child (Ashton-James et al., 2013). In addition, there is a recent trend for parents to be overly involved in their child's life in order to sustain their child's happiness and well-being. New colloquial parenting terms such as "helicopter parenting", "lawnmower parent", and "bulldozer parent" all follow the same idea of wanting to control their child's life to limit any negative experiences that may occur (Locke, Campbell, \& Kavanagh, 2012). The helicopter parenting idea has also been scientifically studied and appears to be undermining adolescents' developing autonomy (Padilla-Walker \& Nelson, 2012). Given these trends may be tied to parents' desire for their children to be happy at extreme levels and the parallels to research showing that excessively valuing happiness could be 
detrimental to one's own wellbeing (Mauss et al., 2011; 2012), this study investigates parental excessive value of their children's happiness. Additionally, given that the excessively valuing happiness measure is relatively new, this study will examine the validity of this new measure. The current study will examine convergent validity by testing if excessively valuing a child's happiness is related to the degree in which parents want their child to be happy. Overall, the goal of this study is to extend the research on excessively valuing happiness to the parenting domain to determine whether or not some parents may excessively value their child's happiness and determine whether this parenting phenomenon co-occurs with expected parental emotion socialization (e.g., up-regulating children's positive emotions) and parenting behaviors (e.g., helicopter parenting).

\section{Emotion Socialization}

One of the first ways children learn about emotions and what emotions to value is through their parents or caregiver. Parental emotion socialization is the process in which the parent intentionally or unintentionally influences children's emotional development, often by the parents' modeling emotion regulation, discussing emotion and reactions with their child and reacting to their child's expression of emotions (Eisenberg, Cumberland, \& Spinrad, 1998). For instance, when a child expresses their emotion, the parent may use it as an opportunity to teach their children about emotion and help them learn how to regulate their emotions (e.g., by providing instructions or advice). There are two general types of emotion socialization: positive affect socialization and negative affect socialization. Positive affect socialization is how a parent socializes a child's positive emotions such as happiness, joy, and excitement. Negative affect socialization is how a parent socializes their child's negative emotions such as anger, sadness, and frustration. 


\section{Negative Affect Socialization}

There is an extensive amount of literature on how parents can socialize their child's negative affect. Negative affect socialization can be performed in adaptive or maladaptive ways. For instance, parents can react to their child's negative affect in an accepting way such as allowing their child to express negative emotion, coach or teach their child how to cope with negative emotions, reject their child's negative emotions, or may not engage in any socialization behavior because the parent is uncertain on how to react (Eisenberg, Cumberland, \& Spinrad, 1998; Paterson et al., 2012;). Parents who downregulate or reject their child's negative emotion (sadness, anxiety, anger) teach their child that these emotions are inappropriate, which is associated with poor outcomes for the child such as poorer emotion regulation and higher anxiety (Fabes, Leonard, Kupanoff, \& Martin, 2001; Garside \& Klimes-Dougan, 2002; Lagace-Seguin \& Coplan, 2005; Snyder, Stoolmiller, Wilson, \& Yamamoto, 2003). The present studies investigate how parents' value and beliefs about their children's happiness corresponds with how they socialize their child's negative emotions. It is predicted that parents who excessively value their child's happiness may be more likely to downregulate their child's negative emotions in hopes that the child stays in a positive mood.

There is some existing research on parents' beliefs about children's emotions and how these beliefs may determine how they will respond to and regulate their children's emotions. The term, meta-emotion philosophy, is used to describe parents' own beliefs about emotions and how they will teach, express, label, and regulate emotions to their children (Gottman, Katz, \& Hooven, 1996; Paterson et al., 2012). Research on parents' meta-emotion philosophy originally focused on negative affect (Gottman et al., 1996), and typically four emotion-related parenting styles (coaching, laissez-faire, dismissing, and disapproving) are distinguished (Gottman \& 
DeClaire, 1997). Coaching is when the parent is more accepting of their child's negative emotions. Parents who coach also use the opportunity to teach the child that it is acceptable to express these emotions and ways to regulate and express emotions in contextually appropriate ways. Laissez-faire parents also are accepting of children's emotions but they do not teach or guide the child's behavior and emotion regulation skills. In contrast, dismissing parents tend to ignore their child's emotions and do not teach their child how to regulate emotions or problemsolve. Similarly, disapproving parents display dismissing behaviors but are harsher, often criticizing and punishing the child's emotional expressions (Gottman \& Declaire, 1997). This research generally shows that parents who are characterized as more emotion-coaching and more accepting of children's emotions are more attentive to and supportive of children's negative emotions (e.g., Gottman, Katz, \& Hooven, 1996; Morey \& Gentzler, 2017) and their children have fewer behavior problems (Hooven, Gottman, \& Katz, 1995; Katz \& Hunter, 2007). Overall, this research demonstrates that parents' meta-emotion philosophy influences their socialization behaviors. The present study extends this research by examining how beliefs about happiness may be associated with parents' socialization behaviors.

\section{Positive Affect Socialization}

Similar to the research on negative affect socialization, there are many different ways parents can socialize and respond to their child's positive affect. For example, parents can model and reinforce different emotion regulation strategies such as savoring and dampening (e.g., Gentzler, Ramsey, \& Black, 2015). Savoring is when a person uses different thoughts or behaviors to upregulate or maintain their positive emotions and is related to higher happiness and self-esteem (Bryant, 2003). Some examples include anticipating, appreciating and cherishing the moment, prolonging the experience, sharing with others, and reminiscing or reflecting on the 
event (Bryant, 2003; Gentzler, Palmer, \& Ramsey, 2016). Conversely, dampening (e.g., thinking negative thoughts about a positive experience or PA) is an emotion regulation response that is related to lower levels of positive affect and higher levels of depressive symptoms or internalizing and externalizing problems (Bijttebier, Raes, Vasey, \& Feldman, 2012; Feldman, Joormann, \& Johnson, 2008; Gentzler et al., 2013).

The socialization of positive affect plays an important role in a child's life. Coaching and teaching positive emotion is correlated to positive child outcomes such as better emotional skills (Denham \& Kochanoff, 2002) and better emotion regulation skills (Southam-Gerow \& Kendall, 2002). Limited research has investigated parents' beliefs about their children's positive affect (Halberstadt et al., 2013; Gentzler, Palmer, Yi, Root, \& Moran, 2018; Katz et al., 2014; Morey \& Gentzler, 2017). For example, parents who thought positive emotions were costly or harmful were less likely to validate children's positive emotions and more likely to downregulate children's happiness (Halberstadt et al., 2013; Katz et al., 2014). In this same sample, mothers who wanted their children to ideally feel more high-arousal positive emotions (e.g., excitement) were more likely to encourage their child to celebrate whereas mothers' desire for low-arousal PA (e.g., calmness) were more likely to encourage affectionate responses in their children (Gentzler et al., 2018). However, the current study expands on this limited research by examining the link between parents' beliefs about emotions (i.e., their value of their child's happiness) and their emotion socialization techniques to their child's positive affect. It is expected that parents who more excessively value their children's happiness will report being more likely to encourage their child to savor and less likely to encourage dampening. Because existing socialization research considers parental upregulate of children's positive affect as healthy and adaptive, the current study is novel by exploring whether some parents who tend to 
up-regulate their children's positive affect may have less adaptive beliefs (i.e., excessive focus on their child's happiness).

\section{Helicopter Parenting and Parental Indulgence}

In addition to potentially up-regulating children's positive affect and down-regulating children's negative affect, parents who excessively value their child's happiness may engage in behaviors similar to parents characterized as helicopter parents and indulgent parents. Helicopter parenting can be described as inappropriate and excessive parenting such as "hovering" or staying close to their child regardless if the child needs them or not (Locke, Campbell, \& Kavanagh, 2012) and extremely concerned for the child's well-being (Padilla-Walker \& Nelson, 2012). The "helicopter" parents tend to emphasize their child's specialness and eagerly try to make sure their children get what they want (Padilla-Walker \& Nelson, 2012). Although helicopter parenting does involve controlling behaviors, it appears to be distinct from other types of parenting control. Specifically, with emerging adults aged 18-29 years, Padilla-Walker and Nelson (2012) conducted a factor analysis and found that helicopter parenting emerged as a separate factor from behavioral control and psychological control. Unlike these forms of control (i.e., behavioral and psychological control), helicopter parenting is associated with positive parenting behaviors, such as parental involvement, guidance, disclosure, and emotional support (Padilla-Walker \& Nelson, 2012). Helicopter parenting is similar to overparenting, where parents protect their child from disappointment and believe that the child needs a constant pleasant life (Locke, Campbell, \& Kavanagh, 2012). Overall, these types of parenting behaviors are associated with lower psychological well-being (LeMoyne \& Buchanan, 2011), lower levels of autonomy and feelings of competency when solving problems (Schiffrin, Godfrey, Liss, \& Erchull, 2014), as well as lower levels of satisfaction with their family life in college students 
(Segrin et al. 2012). These helicopter parenting characteristics were expected to be associated with the characteristics of parents who excessively value their child's happiness due to the similarities of the parents' eagerness to please their child and keep them happy.

Another type of parenting that overlaps with helicopter parenting and is also expected to relate to parents' value of children's happiness is indulgent parenting. Parental indulgence is characterized by parents constantly wanting to satisfy their child's needs and desires (Chen, Liu, \& Li, 2000). Children of indulgent parents are considered "spoiled" because they typically receive everything they want and need from their parents. Maccoby and Martin (1983) refer to a similar type of parenting style as permissive-indulgent where parents are low demandingness but provide levels of emotional support. Similarly, Coccia, Darling, Rehm, Cui, and Sathe (2012) describe indulgent parenting as over-indulging or over-nurturing the child and giving the child too many unnecessary resources. Indulgent parents not only overly indulge their child they are low on parental control and set few rules or consequences for their child's behavior (Coccia et al., 2012). Similar to helicopter parenting, indulgent parenting is associated with negative child outcomes such as lower levels of leadership, social competence, and academic achievement (Chen, Liu, \& Li, 2000). Additionally, parental indulgence was associated with higher levels of emotional and behavioral problems in college students (Cui, Graber, Metz, \& Darling 2016). Given that with both helicopter and indulgent parenting, parents' goal is to make and keep their child happy and satisfied, these parenting styles are expected to be associated with parents' excessively valuing their child's happiness.

\section{Children's Development and Parenting}

Parenting and emotion socialization behaviors can be contingent on the children's development. As children age, they become more mature and responsible and parents may have 
higher expectations for their children's emotion regulation. A study conducted by KlimesDougan and colleagues (2007) examined differences in parental socialization of emotional regulation in youths ages 11 to 16 years old. The study found that older adolescents reported that their parents were more punitive of their emotional displays than did younger adolescents. Additionally, correlational results showed that the older the child, the more likely the parents neglected their child's sadness and fear (Klimes-Dougan et al., 2007). These results are consistent with O'Neal and Malatesta-Magai's (2005) study that found that adolescents reported that their parents were less supportive and engaged in less facilitative approaches to emotion socialization. The effects of emotion socialization also change with age. For example, one study found that supportive parenting in response to negative emotions became less adaptive as children become older (Mirabile, Oertwig, \& Halberstadt, 2016). Specifically, children under 5 years old benefited from parents' supportiveness (e.g., better socioemotional adjustment); however children over 5 years old did not benefit from their parents' supportiveness (Mirabile, Oertwig, \& Halberstadt, 2016). The current study examines parents' value of children's happiness and emotion socialization behaviors across middle childhood and adolescence. Although research has found that children's age plays a role in parents' emotion socialization behaviors, valuing a child's happiness is expected to be a stable trait since it is more a function of the parent than the child.

\section{The Present Studies}

The overarching questions of this research was to investigate if some parents may value children's happiness at extreme levels and what emotion socialization and parenting behaviors are associated with this phenomenon. The concept of excessively valuing happiness is a relatively new area of research. No research has examined if the idea of excessively valuing 
happiness can be applied to another person's happiness and in particular, one's children.

Additionally, no research has examined how parents' beliefs about their children's happiness is linked to parenting behaviors and emotion socialization. The first goal of this research was to validate a new measure of parents' excessively valuing their child's happiness. The second goal of this research was to examine the emotion socialization of parents who excessively value their child's happiness and whether the parents up-regulate or down-regulate their child's positive and negative affect. The third goal was to determine if the parenting styles of individuals who excessively value their child's happiness are similar to helicopter and indulgent parenting. Two studies were used to examine these parenting behaviors. The first study focuses on parents' positive affect socialization with mothers and children between 7 to 12 years old. The second study focuses on parents' negative affect socialization of both mothers and fathers with their adolescent (14 to 18-year-old) children. The second study also includes the adolescents' report on their parents' helicopter and indulgent parenting styles. Both studies have data that can be used to validate the Parents' Value of Children's Happiness scale.

\section{Research Questions and Hypothesis}

Research Question 1: Validate a new measure of parents' excessively valuing their child's happiness using convergent validity.

Hypothesis 1a: Parents who excessively value their child's happiness to a greater degree were expected to want their child to be happier more frequently. Specifically, parents' reports of their excessive value of their child's happiness was expected to positively correlate with parents' reports of how frequently they want their child to be happy. This hypothesis was tested in both studies. 
Hypothesis 1b: The child was expected to corroborate their parents' reports of excessively valuing their happiness. This hypothesis was tested in Study 2 only, where parents' reports of their excessive value of their child's happiness should correlate with the child's report on the extent to which their parents excessively value their own (the child's) happiness.

Research Question 2: Are parents who excessively value their child's happiness at a higher degree more likely to upregulate their child's positive affect?

Hypothesis 2a: Parents who excessively value their child's happiness at higher levels were expected to be more likely to encourage savoring than those who report lower levels of valuing their child's happiness. Thus, parents' reports of their excessive value of their child's happiness should predict their reports of how frequently they encourage savoring. This hypothesis was only tested in Study 1.

Hypothesis 2b: Parents who excessively value their child's happiness at a higher degree were expected to be less likely to encourage dampening than those who do not excessively value happiness to as high of a degree. Parents' reports of their excessive value of their child's happiness should predict parents' reports of how frequently they encourage dampening. This hypothesis was tested in Study 1.

Research Question 3: Are parents who excessively value their child's happiness at higher levels more likely to downregulate their child's negative affect?

Hypothesis 3a: Parents who excessively value their child's happiness to a higher degree were expected to be more likely to reject their child's negative emotion than those who do not excessively value happiness to as high of a degree. Parents' reports of their excessive value of their child's happiness should predict parents' reports of how frequently they reject their child's negative emotions. This hypothesis was only tested in Study 2. 


\section{Research Question 4: Does parents'value of their child's happiness predict parenting}

behaviors?

Hypothesis 4a: Parents who excessively value their child's happiness at higher levels were expected to be more likely to engage in indulgent parenting behaviors than those who excessively value their children's happiness at lower levels. Parents' reports of their excessive value of their child's happiness should predict child's reports of how frequently their parents engage in indulgent behaviors. This hypothesis was tested Study 2.

Hypothesis 4b: Parents who excessively value their child's happiness at a higher degree were expected to be more likely to engage in helicopter parenting behaviors than those who do not excessively value happiness to as high of a degree. Thus, parent' reports of their excessive value of their child's happiness was expected to predict child's reports of how frequently their parents engage in helicopter behaviors. This hypothesis was tested in Study 2.

\section{Study 1}

\section{Method}

\section{Participants}

Participants included 76 mothers and children. Half of the children were boys (52\%) and their ages ranged from 7 to 12 years old $(M=9.34$ years, $S D=1.44)$. The mothers were mostly married $(82.9 \%)$ between the ages of 29 to $56(M=38.8, S D=5.73)$ years old. Majority of the mothers reported their ethnicity as White (85.5\%), 5.2\% reported being African American or Black, 2.6\% Asian American or Asian, 1.3\% Hispanic or Latino, 4\% multi-ethnicity and 1.3\% reported "other." The mothers reported on their highest level of education: $1.3 \%$ completed $11^{\text {th }}$ grade, $6.7 \%$ graduated high school, $14.5 \%$ completed $2-3$ years of college; $39.5 \%$ earned a $4-$ year college degree, $22.3 \%$ completed some graduate school or a 2-3-year graduate degree, and 
$14.5 \%$ earned a doctoral degree. More than half of the mothers' annual household income was over $\$ 100,000(61.7 \%)$. See Table 1 . This sample came from a larger study of 100 mothers. The Valuing Child's Happiness measure was given at the second assessment. Only mothers $(N=79)$ who completed both assessments were eligible to participate. Additionally, three families were excluded from the data due to missing data or being identified as an outlier.

\section{Procedure}

The participants were recruited from the eastern Appalachian area of the United States. Some of the mothers were recruited in-person through events. Flyers also were posted in the community and emails were sent through university or community mailing lists and local pediatricians' offices. Interested participants either came to the lab or completed the study at their home. Parents completed consents and children assented to the research. Both the mother and child completed surveys separately. To ensure the children understood the survey questions, the researcher read the questions out loud to the child. Two discussion tasks were also completed with the mother and child dyad but were not used for this study. Afterwards the families were compensated $\$ 30$ for their participation.

Approximately five months later, mothers and their children were mailed a brief survey that they were asked to complete independently. From this survey, we used Mothers' Value of their Child's Happiness scale. Families received a \$10 gift card for this portion. IRB approval of this study was obtained prior to data collection.

\section{Measures}

Demographics. Mothers completed a demographics questionnaire about themselves and their child which included questions about age, gender, race/ethnic background, household income, marital status, education level, and their relationship to the child. 
Valuing child happiness. Mothers completed a version of the seven-item (Mauss et al., 2011) Valuing Happiness scale that was altered for parents to assess the level they valued their child's happiness. This scale was originally developed to measure the extent to which people value happiness to a potentially extreme degree. Thus, questions for the parenting version were designed to assess parents' extreme need for the child to be happy and negative implications for the parents if their child is not happy. Examples of the questions include, "How happy my child is at any given moment says a lot about how worthwhile my life is", and "Having my child feel happy is extremely important to me". The scores were rated on a 7-point scale $(1=$ strongly disagree to $7=$ strongly agree $)$ and then averaged to create a total score $(\alpha=.82)$.

Ideal affect. Mothers completed an adapted version of the Affective Valuation Index (AVI; Tsai, Knutson, \& Fung, 2006), which measures both parents' desired (ideal) affect for their child and actual affect for the child. For the purpose of this study, the focus is on moderate arousal positive ideal affect, which is a 3-item scale including happy, satisfied, and content $(\alpha=$ .73). The scores were rated on a 5 -point scale $(1=$ never to $5=$ all the time $)$. Item scores are averaged to indicate, ideally, how much the parents' want their child to feel. High-arousal positive (enthusiastic, excited, elated; $\alpha=.83$ ) and low-arousal positive (calm, relaxed, peaceful; $\alpha=.73)$ was be examined on an exploratory basis.

Parents' responses to children's positive events (PRCPE). Mothers completed the PRCPE (Gentzler, Ramsey, \& Black, 2015) that assesses how much the parent encourages their child to savor or dampen in the context of five positive event scenarios involving a positive surprise, and relationship- and achievement-related events. The parents rated the likelihood they would encourage particular responses in their child on a 5-point Likert scale $(0=$ not at all likely to $4=$ very likely). Savoring and dampening were computed by averaging the scores across the 
five events to create subscales. The savoring responses included: share (e.g., "encourage your child to tell a friend or family member about his/her good grade"; $\alpha=.78$ ); express (e.g., “encourage your child to express his/her happiness in some way", $\alpha=.92$ ); mark (e.g., "encourage your child to post his/her project on the refrigerator or somewhere else to mark this achievement"; $\alpha=.67)$; reward (e.g., "reward your child for doing so well in school, such as buying them something special"; $\alpha=.79$ ); celebrate (e.g., "do something to celebrate such as go out to dinner"; $\alpha=.80$ ); reflect on PA (e.g., "encourage your child to think about how good or proud he/she must feel"; $\alpha=.83$ ); reflect on self (e.g., "tell your child how smart he/she is or encourage them to think about it"; $\alpha=.61$ ); affection (e.g., "express affection toward your child such as pat them or hug them"; $\alpha=.72$ ); and thankful (e.g., "encourage your child to be grateful for his/her good grade"; $\alpha=.84$ ). There are three dampening scales that includes: minimize (e.g., "remind your child that it is only one grade in a single class"; $\alpha=.61$ ), focus on negative (e.g., "tell your child he/she probably just got lucky and may never do that well in the future"; $\alpha=.61$ ) and stop talking (e.g., "discourage your child from continuing to talk about the grade after the initial conversation"; $\alpha=.62$ ). Savoring score was calculated by averaging specific strategies (share, express, celebrate, mark, reflect on PA, reflect on self, reward, affection, and thankful; $\alpha$ $=.94$ ), and a dampening score was computed the same way by averaging minimize, stop talking, and focus on the negative $(\alpha=.77)$.

Parental reactions to children's positive emotions (PRCPS). Mothers completed the PRCPS (Ladouceur, Reid \& Jacques, 2002) that assesses parents' reactions to their child expressing emotions in the context of twelve different situations (e.g., "If we are in a restaurant to celebrate a birthday with our family and my child jumps out of his/her chair and shouts "Happy Birthday!", I would...). The mothers rated the likelihood they would react to particular 
responses from their child on a 7-point Likert scale $(1=$ very unlikely to 7 very likely). The scale is divided into four subscales: encouragement $(\alpha=.66)$, explanation $(\alpha=.67)$, reprimand $(\alpha=$ $.83)$, and personal discomfort $(\alpha=.78)$. Mean scores were computed for each of the subscales.

\section{Results}

\section{Preliminary Analysis}

All the variables in the study were examined for accuracy of data entry, missing values, collinearity and the assumptions of multivariate prior to analysis. Expectation maximization imputation (i.e., correlation matrix computed by assuming the shape of a distribution for the missing data) was used for the missing cases after finding no statistically significant deviation from randomness using Little's MCAR test, $p=.75$. To help reduce the extreme skewness, the dampening subscale from the PRCPE measure was transformed by square rooting the mean of the scale and the moderate arousal positive ideal affect subscale was logarithmically transformed. Additionally, one participant was excluded from the analyses after being identified through Mahalanobis distance as a multivariate outlier $(49.76, d f=20, p<.001)$.

Bivariate correlations were conducted to examine the association between mothers' value of their child's happiness and socio-demographic variables (see Table 2). Mothers' yearly household income and education level was negatively correlated with mothers' report of valuing their child's happiness Additionally, mothers' report of their socialization of dampening was negatively correlated to the child's age. T-tests were conducted with the child's gender and the main variables of the study (e.g., parent value of child's happiness, positive emotion socialization, ideal affect) and there were no significant differences.

\section{Primary Analysis}


To addresses the first hypothesis regarding the validity of the Valuing Child's Happiness Scale, bivariate correlations were conducted to examine the relationship between mothers' report of excessively valuing their child's happiness and the child's ideal and actual affect (e.g., high, moderate, and low). Consistent with the hypotheses, mothers' report of valuing their child's happiness was positively correlated with mothers' report of their ideal positive affect for their child. Specifically, the more the mothers reported valuing their child's happiness, the more the mothers ideally wanted their child to experience high arousal positive affect and moderate arousal positive affect, supporting convergent validity (see Table 2).

Eight hierarchal regressions were performed to examine the association of mothers' positive affect socialization and the value of their child's happiness, addressing the second research question (see Tables 3 and 4). The child's age, gender, and household income were used as covariates and entered into the first step, mothers' value of their child's happiness was entered into the second step, and the child's actual affect was entered into the third step for all eight regression models. Each model was performed with eight different dependent variables related to positive emotion socialization: savoring, dampening, child's report of savoring, child's report of dampening, explanation, encouragement, reprimand, and discomfort. Only one regression model was significant: the mothers' report of valuing their child's happiness significantly predicted their report of their socialization of savoring (see Table 3 and 4).

To complement the regression models and to increase parsimony and account for covariance among the dependent variables, a structural equation model was conducted. The mothers' value of their child's happiness was used as a predictor of each of the emotion socialization behaviors: savor, dampen, explanation, encourage, reprimand, and discomfort controlling for household income (Figure 1). The model fit was poor (Comparative Fit Index 
$(\mathrm{CFI})=.07, \chi 2 / \mathrm{df}$ ratio $=6.24$, root mean square error of approximation $(\mathrm{RMSEA})=.26)$. To improve model fit, non-significant parameters (encouragement and discomfort) were removed $\left(\mathrm{CFI}=.63, \chi^{2} / d f\right.$ ratio $\left.=2.52, \mathrm{RMSEA}=.14\right)$. Additionally, modification indices suggested covarying savor and dampen. Therefore, both variables were covaried, which makes conceptual sense because the variables were significantly correlated $(r=-.28 ; \mathrm{CFI}=.475, \chi 2 / \mathrm{df}$ ratio $=3.15$, RMSEA = .17). The model fit remained poor thus savoring and reprimand were covaried suggested by the modification indices $(\mathrm{CFI}=.52, \chi 2 / \mathrm{df}$ ratio $=3.21, \mathrm{RMSEA}=.17)$. Again, this makes conceptual sense to covary these constructs due to the variables being significantly correlated with each other $(r=-.24)$. Lastly, modification indices suggested covarying explanation and reprimand, making conceptual sense based on the fact that these variables were significantly correlated with each other $(r=.44)$. The final model established a good fit, $\chi^{2}=$ $8.75, p=.27, \mathrm{CFI}=.95, \chi 2 / \mathrm{df}$ ratio $=1.25, \mathrm{RMSEA}=.06($ Figure $1 \mathrm{~b})$. Consistent with the results of the regression models, only savoring was positively associated with mothers' valuing of their child's happiness.

\section{Discussion}

Overall, the study investigated the new measure of parents' valuing their child's happiness and examined its association with positive emotion socialization. Supporting the first hypothesis, the Valuing Child's Happiness measure showed evidence of convergent validity. Parents who excessively valued their child's happiness to a greater degree also reported wanting their child to be happier more frequently. Specifically, parents' reports of their value of their child's happiness was positively correlated with parents' reports of how frequently they wanted their child to experience both high positive arousal (i.e., enthusiastic, excited, elated) and moderate positive arousal (i.e., content, satisfied, happy). These findings are consistent with the 
research on excessively valuing happiness. Individuals who excessively value happiness set high standards for their happiness meaning that they create happiness goals (e.g., feel happy all the time) that are unrealistic (Ford \& Mauss, 2014). In the present study, parents are setting high standards for their child's happiness, such that they very frequently want their child to ideally feel high positive arousal, which may be unrealistic. Setting these potentially unreasonable standards for happiness is thought to be related to lower levels of happiness (Ford \& Mauss, 2014; Mauss et al., 2011). It is important to examine what personal characteristics make an individual set these unrealistic goals either for themselves or their children to further understand why parents excessively value their child's happiness.

The study also supports the notion that mothers' value of their child's happiness plays a role in their positive emotion socialization behaviors. As predicted in the hypothesis, the more the mothers' valued their child's happiness, the more likely the mother socialized their children to savor PA. These results remained significant even when accounting for the child's actual affect, suggesting that mothers value their child happiness regardless of their child's actual emotion (e.g., negative or positive). However, contrary to the hypothesis, socialization of dampening PA was not correlated with mothers' valuing of their child's happiness. Additionally, mothers' value of their child's happiness did not predict any other positive affect socialization behaviors (encouragement, explanation, reprimand, and discomfort). These findings indicate that mothers' who value their child's happiness are consistent with research showing that college students who excessively value their own happiness use more savoring strategies (Gentzler et al., 2016). Encouraging a child to savor positive emotions and happiness can be beneficial for a child. For example, one study found that the more mothers encouraged the expression of positive emotions in their child with low self-control, the less the mothers' reported on their child's 
externalizing behaviors (Yi, Gentzler, Ramsey, \& Root, 2016). Another study found that mothers' encouragement of savoring positive affect was positively correlated with their child's own savoring (Moran, Root, Vizy, Wilson, \& Gentzler, 2018). Additionally, male adolescents’ whose mothers encouraged positive affective displays, demonstrated better emotion regulation (e.g., maintained positive emotions for an extended amount time) during an interaction task (Yap., Allen, \& Ladouceur, 2008). The present study highlights the notion that excessively valuing a child's happiness is associated with beneficial parental positive emotion socialization behaviors which may contribute to positive child outcomes.

There are several limitations to this study. One of its primary limitations is its sample characteristics. Because the present study's sample was only mothers, future studies should examine fathers to explore whether there are parental emotional socialization differences relating to valuing a child's happiness. Additionally, because the present study's sample was relatively small and predominately white, future studies should examine these results with a larger diverse sample to further generalize the findings. The present study only used convergent validity to validate the Valuing Child's Happiness measure. Future studies should utilize various methods of validity (e.g., concurrent, predictive, discriminant, etc.) to provide more justification for the psychometric properties of the measure. Lastly, the present study only examined positive emotion socialization behaviors. Future studies should examine valuing a child's happiness and its implications on negative emotion socialization behaviors to better understand the full range of emotion socialization. Despite these limitations, the current study was the first to explore mothers who excessively value their child's happiness and their positive emotion socialization behaviors. 


\section{Study 2}

Study 2 was, in part, designed to further explore how parents' value of children's happiness may have implications on parenting behaviors. First, in Study 2, we sought to validate the parents' valuing happiness measure with both a parent-reported measure (i.e., how parents ideally want their adolescents to feel, similar to Study 1) and also using adolescent-reported questions. Second, Study 2 allowed us to test the association between valuing happiness and negative affect socialization in parents. Third, we were able to include adolescents' report on their parents' parenting behaviors such as helicopter and indulgence parenting styles. Overall, the second study could help to validate the measure of parents' excessively valuing their child's happiness and expand on the examination of parenting behaviors and socialization in individuals who may excessively value happiness.

The study's sample and methods were similar to Study 1 except that in Study 2, the youth were high school adolescents and both mothers and fathers were included. Research on fathers are limited and some differences between mothers and fathers have been found in terms of emotion socialization such that mothers are more involved and expressive in their child's emotions (e.g., Klimes-Dougan et al., 2007) and fathers are more likely to be punitive and minimize their child's displays of negative emotions (e.g., Eisenberg, Fabes, \& Murphy, 1996). Thus, it is important to include father reports to expand on the research and examine any differences in parenting compared to mothers. The adolescents were recruited in high schools from the eastern area of the United States and were asked for their parental involvement as well. To assess the negative affect socialization, parents reported on the degree to which they engaged in various responses to their child's negative emotions. It was predicted that the more a parent values their child's happiness the more likely the parents will reject their child's negative affect 
than parents who do not value happiness at a high degree. It also was predicted that these parents will be more likely to engage in helicopter and indulgent parenting than parents who do not value happiness at a high degree.

\section{Method}

\section{Participants}

The present study included 116 families comprising adolescents between the ages of 14 and 18 years old. From the sample, 59 had only mothers participate in the study, 17 had only fathers participate in the study and 40 had both parents participate in the study. Families were generally two-parent ( $84 \%$ of the parents were married) and highly educated $(81.8 \%$ had a 4 -year college degree or higher). Most of the sample was enrolled in $9^{\text {th }}$ and $10^{\text {th }}$ grade $(91 \%)$ and $61 \%$ of the sample identified themselves as males. The ethnicity of the adolescents in the sample included White/Caucasian Americans (78.3\%), Black or African Americans (9.8\%), Hispanic or Latino Americans (1.4\%), Asian or Asian Americans (2.8\%), Pacific Islander or Native Hawaiians (0.7\%), and other or multiethnicities/races (5.6\%). See Table 1 for full sample descriptions. The participants came from a larger sample of 143 adolescents but were excluded from this study because they did not have a parent participate $(n=27)$.

\section{Procedure}

The adolescents were recruited from two high schools in Pennsylvania. During school periods, the research team distributed packets for the high school students to take home to their parents. The packet included an overview of the study, contact information sheet, and an informed consent form for the caregiver. The adolescents interested in participating were required to return the forms. Four days after distributing the packets, the research team administered questionnaires to the students who returned the informed consent forms. The 
students had approximately 45 minutes to complete the questionnaire and afterwards were compensated \$20 for their participation. Parent reports were collected based on the parent's preference, either online through the Survey Monkey website or by completing a hard copy of the survey and mailing it to the research team. The parents also consented to participate before completing the questionnaire. The parents were mailed $\$ 20$ for participation.

\section{Measures}

Demographics. Adult participants filled out a demographics questionnaire about themselves and their adolescent which included age, gender, race/ethnic background, household income, marital status, education level, and their relationship to the adolescent. The adolescent participants' questionnaire asked about their age, gender, and ethnicity.

Parents' valuing child happiness. Both mothers and fathers completed the same sevenitem Valuing Child's Happiness scale from Study 1 that was altered for parents to assess the level they valued their child's happiness. The scores were rated on a 7-point scale $(1=$ strongly disagree to $7=$ strongly agree $)$ and then averaged to create a total score $(\alpha=.82)$.

Children's beliefs about parents valuing child happiness. Adolescents completed two items pertaining to each parent to assess the level their parents (both mother and father) valued their own happiness. Questions from the scale included, "How important is your happiness to your mother/father?" and "Do you feel like you are letting your mother/father down if you are not happy?." The scores were rated on a 7 -point scale $(1=$ not at all to $7=$ very $m u c h)$ and then averaged to create a total score for each parent (mothers: $r=.23$; fathers: $r=.40$ ).

Ideal affect. Both parents completed an adapted version of the Affective Valuation Index (AVI; Tsai, Knutson, \& Fung, 2006), which measures both parents' desired (ideal) for their child and actual affect for the child. Given the focus of this study, the 3-item moderate-arousal positive 
ideal affect (i.e., happy, content, satisfied) scale was most relevant. The items were rated on a 5point scale $(1=$ never to $5=$ all the time $)$. Item scores are averaged to indicate, ideally, how much the parents want their child to feel various types of positive emotions $(\alpha=.73)$. Higharousal positive (enthusiastic, excited, elated; $\alpha=.83$ ) and low-arousal positive (calm, relaxed, peaceful; $\alpha=.84$ ) were examined on an exploratory basis.

Parental meta-emotion philosophy. Both mothers and fathers completed the Emotion Related Parenting Styles (ERPS; Paterson et al., 2012) which is a 20-item parent-report questionnaire where responses are rated on a 5-point Likert-type scale $(1=$ always false to $5=$ always true). ERPS measures parents' emotion-related parenting styles such as accepting, rejecting, and coaching negative emotions. The ERPS has four subscales: accept (e.g. "I want my child to experience anger"; $\alpha=.67$ ), reject (e.g. "When my child is angry, my goal is to get him or her to stop"; $\alpha=.58$ ), coach (e.g. "When my child is sad, we sit down and talk over the sadness"; $\alpha=.75$ ), and uncertainty/ineffectiveness (e.g. "When my child is angry, I'm not quite sure what he or she wants me to do"; $\alpha=.79$ ). Each subscale contains five statements. The total score on each subscale is averaged, the higher scores indicates greater agreement with the beliefs and behaviors about children's negative affect. While rejecting and coaching both downregulate negative affect, it is predicted the parent is more likely to reject their adolescent's emotion because it is more immediate. A parent who is eager to keep their child happy may choose an immediate resolution rather than coaching which may be more time consuming. Although rejecting behaviors is the focus of this study, the other subscales were examined as an exploratory basis.

Helicopter parenting. Adolescents completed a 5-item questionnaire (Padilla-Walker \& 
Nelson, 2012) that measured the adolescents' report on both their mother's and father's helicopter parenting on a 5-point scale $(1=$ not at all like him/her to $5=$ very much like him/her $)$. This measure was validated on emerging adults $\left(M_{\mathrm{age}}=19.65\right.$; Padilla-Walker $\&$ Nelson, 2012). A few sample items include: "Makes important decisions for me (e.g., what activities I do, who my friends are)" and "Solves any crisis or problem I might have." Higher scores indicate higher levels of helicopter parenting $(\alpha=.79)$.

Parental indulgence. Adolescents completed 3 items by Chen, Liu, and Li (2000) that have been used to assess the likelihood their parents engage in indulgent behaviors on a 5-point scale $(1=$ not at all like him/her to 5= very much like him/her $)$. The items included "Does everything for me at home," "Buys anything for me if I want it" and "Lets me do whatever I like to do." Higher scores indicate higher levels of adolescents' perception of parental indulgence ( $\alpha$ $=.65)$.

\section{Results}

\section{Preliminary Analysis}

The variables in the study were examined for accuracy of data entry, missing values, collinearity and the assumptions of multivariate prior to analysis. After finding no statistically significant deviation from randomness using Little's MCAR test, $p=.20$, expectation maximization (EM) imputation was utilized for the missing cases. One participant was excluded from the analyses after being identified through Mahalanobis distance as a multivariate outlier $\left(50.73, X^{2}=20, \mathrm{p}<.001\right)$.

Bivariate correlations were conducted to examine the association between sociodemographic variables and mothers', fathers', and adolescents' report on value of happiness (see Table 5). Mothers' value of their child's happiness (teen report) was positively correlated to the 
yearly household income. A paired sample t-test was conducted to compare mothers' and father' reports on the study's main variables. Additionally, paired sample t-tests were conducted to compare the adolescents' report on their mothers' and fathers' parenting behaviors. There was a significant difference in the adolescent-reported scores for mothers' valuing their adolescent's happiness $(M=5.37, S D=1.29)$ and fathers' valuing their adolescent's happiness $M=5.09, S D$ $=1.44) ; t(130)=-2.17, p=0.03$. There was also a significant difference in adolescent-reported helicopter parenting where mothers $(M=2.71, S D=.95)$ were rated higher than fathers $(M=$ $2.46, S D=.81) ; t(130)=-3.53, p=0.001$. Lastly, there was a significant difference in adolescent-reported indulgent parenting where mothers $(M=2.90, S D=.92)$ were rated higher than fathers' indulgent parenting $(M=2.55, S D=.90) ; t(130)=-3.88, p<0.001$.

Bivariate correlations were also conducted to examine the relationship between parents' (both mothers and fathers) value of their adolescent's happiness and the study's main variables (i.e., negative emotion socialization and ideal affect; see Table 5). Mothers' report on valuing their adolescent's happiness was positively associated with rejecting their adolescent's negative affect and indulgent parenting behaviors. Mothers' report on valuing their adolescent's happiness was also positively correlated with uncertainty on how to handle their adolescent's negative affect. Fathers' report of valuing their adolescent's happiness was positively correlated with their adolescent's actual high arousal positive affect. Additionally, fathers' report of valuing their adolescent's happiness was marginally correlated with accepting their adolescent's negative affect. The adolescent's report on the level their parents valued their happiness was significantly associated with helicopter and indulgent parenting behaviors. For example, adolescents' report on the level their mothers valued their happiness was positively correlated with their report of their mothers' helicopter and indulgent behavior. Similarly, adolescents' report on the level their 
fathers valuing their happiness was positively correlated with the fathers' helicopter and indulgent behavior.

\section{Primary Analysis}

To address the first research question, the validity of the parents' value of children's happiness scale was examined. Consistent with the hypothesis, mothers' report of valuing their adolescent's happiness was positively correlated with the adolescent's ideal high (i.e., enthusiastic, excited, elated) and moderate (i.e., happy, content, satisfied) positive affect. The more the mothers reported valuing their child's happiness, the more the mothers ideally wanted their child to experience high arousal positive affect and moderate arousal positive affect. However, this correlation was not significant for fathers. To further validate this measure, adolescents' report on the degree in which their parents' value their own happiness was correlated with parents' report of valuing their child's happiness. This association was not significant for mothers nor fathers.

To test the hypothesis pertaining to valuing adolescent's happiness and its association with negative affect socialization, eight hierarchical regressions were conducted (see Tables 6 and 7). Household income was correlated with various outcome variables (e.g., coach, uncertainty, children's beliefs about parents valuing child happiness) and previous research has shown that parental emotion socialization strategies varies by both age and gender (e.g., KlimesDougan et al., 2007; O’Neal \& Malatesta-Magai, 2005). Therefore, the adolescent's age, gender and annual household income were used as covariates and entered into the first step of the regression model. Valuing adolescents' happiness was included in the second step and the adolescent's actual affect was added to the third step. The first four models (Table 6) examined mothers' report on valuing their adolescent's happiness and the remaining four models (Table 7) 
examined fathers' report on valuing their adolescent's happiness; each model predicting negative emotion socialization belief (e.g., accept, reject, coach, uncertainty). As predicted, mothers' report on valuing their adolescent's happiness significantly predicted mothers' rejection of their adolescent's negative affect. Mothers' report on valuing their adolescent's happiness also significantly predicted mothers' uncertainty on how to handle their adolescent's negative affect. Fathers' report on valuing their adolescent's happiness was also marginally predictive of fathers' rejection of their adolescent's negative affect. Similar to mothers, fathers' report on valuing their adolescent's happiness was associated with fathers' uncertainty on how to handle their adolescent's negative affect.

To test the hypothesis that parental value of adolescent's happiness would relate to more helicopter and indulgent parenting, four additional hierarchical regression was conducted (see Table 8). Mothers' report of valuing their adolescent's happiness did not predict helicopter or indulgent parenting behaviors. Fathers' report on valuing their adolescent's happiness marginally predicted helicopter parenting, but this association was no longer significant after controlling for adolescents' actual affect.

Structural equation modeling was conducted to further examine the regression results, increase parsimony and account for covariance among the dependent variables. Two models were created, one for mothers and one for fathers. Parents' value of their adolescent's happiness was used as a predictor of negative emotion socialization beliefs (e.g., accept, reject, coach, uncertainty) and parenting behaviors (e.g., helicopter and indulgent). The model for mothers did not provide a good fit (Figure $2 \mathrm{a}), \mathrm{CFI}=.75, \chi 2 / d f$ ratio $=2.92, \mathrm{RMSEA}=.12$. After reviewing the modification indices, accepting NA was covaried with rejecting NA, coaching NA, and uncertainty of handling NA. Additionally, uncertainty of handling NA was covaried with 
coaching NA and rejecting NA. Lastly, helicopter parenting and indulgent parenting were covaried. The final model provided good fit (Figure $2 \mathrm{~b}$ ), $\chi^{2}=15.46, p=.08, \mathrm{CFI}=.93, \chi^{2} / d f$ ratio $=1.72, \mathrm{RMSEA}=.07$. Identical to the regression model, mothers' value of their adolescent's happiness was associated with greater levels of rejecting, uncertainty, and indulgent parenting behaviors.

A structural equation model was then conducted for father's value of their adolescent's happiness as a predictor of negative emotion socialization beliefs (e.g., accept, reject, coach, uncertainty) and parenting behaviors (e.g., helicopter and indulgent). The original model did not predict good model fit (Figure 3a), $\mathrm{CFI}=.06, \chi^{2} / d f$ ratio $=7.57, \mathrm{RMSEA}=.22$. Modification indices suggested covarying helicopter parenting and indulgent parenting. Covarying these constructs improved model fit $\chi^{2}=19.48, p=.15, \mathrm{CFI}=.95, \chi 2 / d f$ ratio $=1.39, \mathrm{RMSEA}=.05$. Consistent with the regression model, fathers' value of their adolescent's happiness was only associated with rejecting and uncertainty emotion socialization beliefs. However, fathers' value of their adolescent's happiness did not predict any of the parenting behaviors (Figure 3b).

\section{Discussion}

The present study examined the parents' value of their child's happiness scale and its possible association with negative emotion socialization and parenting among adolescents. The study further supports the convergent validity of the Valuing Child's Happiness scale. As predicted, parents' excessively value of their adolescent's happiness was positively correlated with parents' report of how frequently they wanted their adolescents to experience both high positive arousal (i.e., enthusiastic, excited, elated) and moderate positive arousal (i.e., content, satisfied, happy). However, these results were only true for mothers, not fathers. Unfortunately, the hypothesis that parents' reports of excessively valuing their adolescent's happiness would 
corroborate adolescent's report on the extent to which their parents excessively value their own (the adolescent's) happiness was not supported. Other research has found parent-child discrepancies between parent and child report such that parent reports are often inconsistent with child reports (Tein, Roosa, \& Micheals, 1994). Research also shows that the more negative perceptions adolescents had on parenting behavior (compared to their parents), the more internalizing problems and less social competence the adolescents had (Guion et al., 2009). Although parent and adolescents' reports were not associated in the current study, these questions should be further examined to understand the role that adolescents' perception of their parents' value of their happiness plays on the adolescent and whether discrepancies between parent- and child-report is meaningful.

The study also examined the associations between parents' value of their adolescent's happiness and its association with negative emotion socialization. As predicted, parents (both mother and fathers) who valued their adolescent's happiness at higher levels were more likely to believe that they should reject their adolescent's negative emotion. These findings may suggest that parents are so eager for their child to be happy, they do not want their child to express any negative emotions. Therefore, the parents believe they must reject these expressions. One of the characteristics of excessively valuing happiness is engaging in counterproductive actions to maintain happiness (Ford \& Mauss, 2014). Rejecting a child's negative emotions is counterproductive because dismissing a child's negative emotions have been related to negative outcomes for the child (Fabes, Leonard, Kupanoff, \& Martin, 2001; Garside \& Klimes-Dougan, 2002; Lagace-Seguin \& Coplan, 2005; Snyder, Stoolmiller, Wilson, \& Yamamoto, 2003). Parents who engage in these behaviors may believe that rejecting negative affect is productive and will maintain their child's happiness. Although these parents' intentions may be to maintain 
their child's positive emotions and decrease negative emotions, rejecting a child's negative emotions is associated with negative outcomes, such as poor emotion regulation and higher anxiety (e.g., Lagace-Seguin \& Coplan, 2005; Snyder et al., 2003).

An unexpected finding arose among parents who valued their adolescent's happiness at higher levels. The more parents valued their adolescent's happiness the more likely parents were uncertain on how to handle their adolescent's negative emotions and use ineffective ways to handle their adolescent's negative emotions. It is possible that if parents are overly concerned that their child remain happy, when their child is not happy, the parents get overwhelmed and are unsure how to handle negative emotions. Again, this is consistent with one of the characteristics of excessively valuing happiness (e.g., engaging in counterproductive actions to maintain happiness; Ford \& Mauss, 2014). Similar to rejecting a child's expression of negative emotions, parents' feelings of uncertainty and ineffectiveness in negative emotion socialization has been linked to greater parental distress, and more punitive and minimizing reactions toward their child's negative emotions (Paterson et al., 2012). These findings provide new evidence that excessively valuing a child's happiness may contribute to maladaptive negative emotion socialization practices.

Parents' value of their adolescent's happiness differentially predicted parenting behaviors, showing some evidence for the hypotheses. As predicted, parents who excessively valued their adolescent's happiness at higher levels were more likely to engage in indulgent behaviors, but only for mothers. This association became non-significant after controlling for adolescent's age, adolescent's gender, and household income in the regression models. These findings may only be significant for mothers due to the fact that fathers may play a more authoritarian role than mothers, and are perceived as protectors and discipliners (Finley, Mira, \& 
Schwartz, 2006). Although indulgent parenting was associated with mothers' value of their adolescent's happiness, helicopter parenting was not associated with mothers' value of their adolescent's happiness. Yet consistent with the hypothesis, fathers who excessively valued their adolescent's happiness at higher levels, marginally predicted more helicopter parenting behaviors. However, after controlling for adolescents' actual affect this association was no longer significant suggesting that these helicopter parenting behaviors are partially based on adolescent's emotion. When examining adolescent's report of parenting behavior, the final research question was supported. Specifically, adolescents' report on how much their parents value their own (the adolescent's) happiness was positively correlated with mothers and fathers indulgent and helicopter parenting behaviors. When adolescents perceive that their parents excessively value their happiness, the adolescents are more likely to report that their parentis engage in both helicopter and indulgent parenting. Again, adolescents' perception of parenting behaviors is important to study due to its association with negative outcomes (e.g., Guion et al., 2009). Future studies should further examine adolescents' perception of their parents valuing their happiness and its relationship with other parenting behaviors (e.g., psychological control, monitoring, behavioral control).

Although this study provided novel findings, this study had a few limitations. The study's sample were majority educated White families with high income levels. Future studies should examine this research with diverse populations to ensure generalizability of the results. Additionally, future studies should examine these results longitudinally to assess whether the significant association among the variables remain consistent or change over time. The study only examined negative emotion socialization beliefs, although emotional beliefs and behaviors are highly correlated (Paterson et al., 2012), future research should investigate both negative and 
positive emotion socializations behavior to better understand this association with parents' value of their child's happiness. Lastly, this study only focuses on adolescents and previous research found differences in emotion socialization behaviors based on the child's age (Dix, 1991; Klimes-Dougan et al., 2007; O’Neal \& Malatesta-Magai, 2005). Future studies should explore whether the results from the present study holds true with younger children. Although the study had its limitation, it provided further insight into the association between excessively valuing a child's happiness and parental negative emotion socialization beliefs and parenting behaviors.

\section{General Discussion}

The current research provided an initial investigation into parents' value of children's happiness and examining a new Valuing Child's Happiness scale. In both of the studies, convergent validity was shown because the parents' value of their child's happiness was correlated with parent's report of how ideally, they wanted their child to experience positive emotions. Parents who valued their child's happiness to a high degree, ideally wanted their child to feel not only happy more often, (e.g., moderate positive arousal) but also excited (e.g., high positive arousal). One of the key components of excessively valuing happiness is the unrealistic goals individuals set regarding happiness. These parents want their child to feel high intensity positive affect most of the time which is unrealistic, thus further stressing the degree in which these parents obsess over their child's happiness. These results remained consistent across studies with samples of children with different age ranges (e.g., 7-12 and 14-18 years-old) indicating age does not determine whether parents will value their child's happiness.

Although adolescents' perception of parents' value of their happiness was not associated with parents' perception in Study 2, future research should further consider how adolescents perceive their parents' beliefs and behaviors. It is possible some view their parents as supportive 
and caring about their happiness the right amount, whereas others may view their parents as overly concerned, and it may be important to tease these views apart. Various types of validation methods (e.g., divergent, concurrent, predictive validity) should be utilized in future studies to further examine the psychometric properties of this new measure. Additionally, future studies should further develop this new measure. Currently this measure only assesses parents' beliefs regarding happiness. This measure could be further developed by adding questions that assess parenting behaviors of individuals who excessively value their child's happiness because currently the measure only assesses the degree parents agree or disagree with statements regarding valuing their child's happiness. The measure should also include the frequency parents have these beliefs regarding their child's happiness. It is possible that the more frequent parents have these beliefs the worse the outcomes may be for the parent and/or child.

This study also examined whether parents' value of their child's happiness predicted their emotion socialization. The findings from both studies indicated significant association between parents' value of their child's happiness and both positive and negative emotion socialization behaviors. Specifically, the more parents valued their child's happiness the more likely they encouraged their child to positive affect. Additionally, parents who valued their child's happiness at high levels were more likely to reject their child's negative affect and were uncertain how to handle their child's expression of negative emotions. These results were consistent for both mothers and fathers, indicating that parents who excessively value their child's happiness socialize their child's negative emotions in similar ways. These emotion socialization behaviors are both adaptive (e.g., savoring) and maladaptive (e.g., rejecting and uncertainty). 
The studies examined two different developmental periods. One study focused on middle childhood (i.e., 7 to 12-year olds) whereas, the second study examined adolescence (i.e., 14 to 18-year olds). Research has found that parenting behaviors and beliefs might vary by age or developmental period of the child. For example, parents are known to be more punitive toward their older children's negative emotions (e.g., neglect their children's sadness and fear; KlimesDougan et al., 2007). Additionally, O’Neal and Malatesta-Magai (2005) found that adolescents reported that their parents were less supportive and engaged in less facilitative approaches to emotion socialization (e.g., used less reward and more neglect to negative emotions). The present study suggests that parents who excessively value their child's happiness to a higher degree are more likely to reject their child's negative affect. However, it may be the case that these results are only true for adolescents but not younger children. Unfortunately, we did not have measures of parental responses to negative emotions in the study with children. Due to the mixed findings, future studies should investigate positive and negative emotion socialization with a sample of both children and adolescents to examine whether these socialization practices relate to parents' value of children's happiness in one or both age periods. If the results are consistent across age periods, the children (of parents who excessively value their happiness) are receiving mixed messages. These children are learning both adaptive (i.e., savor PA) and maladaptive (i.e., reject NA) emotion regulation strategies. Emotion socialization has important implications for children's emotion regulation strategies (Eisenberg, Cumberland, \& Spinrad, 1998), thus it is important to determine the resulting effects on the child.

The study highlights the similar behaviors of individuals who value their own happiness and parents who value their child's happiness. For example, individuals who excessively value happiness are likely to set unrealistic standards for happiness and parents who excessively value 
their child's happiness set unreasonable standards regarding happiness for their child (e.g., ideally want their child to experience high positive arousal). Additionally, individuals who excessively value happiness engage in counterproductive behaviors to attain happiness (Gentzler et al., 2016) and parents that value their child's happiness respond to their child's negative emotions in counterproductive ways (e.g., reject, use ineffective strategies, uncertainty). These results further support the notion that valuing one's own happiness shares similar characteristics as valuing a child's happiness. Parents may project their own emotion beliefs onto their child (Gentzler, Palmer, Yi, Root, \& Moran, 2018). Future studies should investigate the association between parents' value of their own happiness and their child's happiness to examine whether these values are transferrable.

Lastly, this study sought to examine the relationship between parents' value of their child's happiness and their parenting behaviors. After controlling for potential covariates, parents' value of their child's happiness was not related to their helicopter nor indulgent parenting behaviors. Parenting behaviors were reported by adolescents, future studies should examine whether these results are consistent with parent-report or use observation methods that may be more objective. Additionally, there are various types of parenting styles and behaviors (e.g., authoritative, authoritarian, psychological control) that should be examine in relation to parents' value of their child's happiness. These parenting behaviors can predict different outcomes for a child (Luyckx, Soenens, Vansteenkiste, Goossens, \& Berzonsky, 2007; Nelson \& Padilla-Walker, 2011). It is important to examine this relationship (i.e., valuing child's happiness and parenting behaviors) to better understand the parenting behaviors of parents who excessively value their child's happiness. Future studies should further examine whether parents' value of 
their child's happiness is related to other parental or child characteristics to better understand its influence on the child's outcome.

The findings for the current studies must be examined in the context of its limitations. The sample of both studies were predominately White and relatively low sample sizes. There is research that shows that emotion socialization and parenting practice can differ based on an individual's race, culture, or ethnicity (e.g., Garrett-Peters et al., 2008; Parker et al, 2012; Saw \& Okazaki, 2010). Another socio-demographic variable that could be further examined is household income. The studies included predominantly middle- to upper-class samples. Studies 1 and 2 found mixed results related to household income and parents' value of their child's happiness. In Study 1, there was a negative relationship between income and parents' value of their child's happiness (i.e., parents with lower income valued their child's happiness to a higher degree), whereas in Study 2 there was a positive relationship (i.e., mothers with higher income valued their child's happiness to a higher degree). Given these contradictory findings more research is needed, ideally with a larger and more ethnically, racially, and socio-economically diverse sample size to better generalize the results.

Other limitations are the study design. This study was a cross-sectional design, which limits the ability to assess intra-individual change and limits the ability to assess the direction of the associations. Future studies, should examine this research longitudinally to examine whether these constructs remain stable or change over time. Additionally, the relationship between parents' value of their child's happiness and their parental emotion socialization behaviors were only examined for linear relationships (i.e., using linear regression). However, valuing a child's happiness and parental emotion socialization behaviors and beliefs could have a curvilinear relationship. For example, parents who value their child's happiness at extreme levels or very 
low levels may lead to more maladaptive emotion socialization behaviors, whereas parents' who value their child's happiness at average levels may use more adaptive emotion socialization behaviors. Thus, future exploratory analyses should examine nonlinear associations.

Future analyses should also examine the role of parent or child sex as a moderator of the relationship between parents' value of their child's happiness and parental emotion socialization. For example, research has found that parents are more likely to punish their son's display of sadness or fear (Eisenberg et al., 1999) and anger (Klimes-Dougan et al., 2007). Not only can child's gender play a role in parenting behaviors, parents' gender can influence their parenting behaviors. For example, fathers may play a more authoritarian role than mothers, and are perceived as protectors and discipliners (Finley, Mira, \& Schwartz, 2006). Given that parents' and child's gender play a role in parenting behavior and beliefs, future studies should examine these moderating factors when studying the association between parents' value of their child's happiness and parental emotion socialization behaviors. Lastly, these data relied solely on selfreport and/or parent-report. Future studies should utilize observational data on specific constructs (e.g., emotion socialization, parenting behavior) to better understand these constructs in a more naturalistic setting.

The idea of excessively valuing one's happiness is a relatively new idea, along with excessively valuing one's child's happiness. The studies found evidence of convergent validity, further validating the new Valuing Child's Happiness measure. Future studies should utilize this new measure to further test its validity and its association to parenting behaviors. In conclusion, these findings offer insight on parental emotion socialization behaviors and provides the groundwork for future studies on this new construct of parents excessively valuing their child's happiness and its possible negative implications. More research should be directed toward 
parents' values of emotions when examining their socialization and parenting behaviors in hopes of preventing or intervening possible negative outcomes for the child. 


\section{References}

Ashton-James, C. E., Kushlev, K., \& Dunn, E. W. (2013). Parents reap what they sow: Child centrism and parental well-being. Social Psychological and Personality Science, 4(6), $635-642$.

Bhattacharyya, M. R., Whitehead, D. L., Rakhit, R., \& Steptoe, A. (2008). Depressed mood, positive affect, and heart rate variability in patients with suspected coronary artery disease. Psychosomatic Medicine, 70(9), 1020-1027.

Bijttebier, P., Raes, F., Vasey, M. W., \& Feldman, G. C. (2012). Responses to positive affect predict mood symptoms in children under conditions of stress: A prospective study. Journal of Abnormal Child Psychology, 40(3), 381-389.

Bryant, F. (2003). Savoring Beliefs Inventory (SBI): A scale for measuring beliefs about savouring. Journal of Mental Health, 12(2), 175-196.

Chen, X., Liu, M., \& Li, D. (2000). Parental warmth, control, and indulgence and their relations to adjustment in Chinese children: a longitudinal study. Journal of Family Psychology, 14(3), 401.

Chida, Y., \& Steptoe, A. (2008). Positive psychological well-being and mortality: a quantitative review of prospective observational studies. Psychosomatic Medicine, 70(7), 741-756.

Coccia, C., Darling, C. A., Rehm, M., Cui, M., \& Sathe, S. K. (2012). Adolescent health, stress and life satisfaction: The paradox of indulgent parenting. Stress and Health, 28(3), 211221.

Cohen, S. \& Pressman, S. D. (2006). Positive affect and health. Current Directions in Psychological Science, 15(3), 122-125. 
Cui, M., Graber, J. A., Metz, A., \& Darling, C. A. (2016). Parental indulgence, self-regulation, and young adults' behavioral and emotional problems. Journal of Family Studies, 1-17.

Danner, D. D., Snowdon, D. A., \& Friesen, W. V. (2001). Positive emotions in early life and longevity: findings from the nun study. Journal of Personality and Social Psychology, $80(5), 804$.

Diener, E. (1984). Subjective well-being. Psychological Bulletin, 95, 542-575.

Dix, T. (1991). The affective organization of parenting: Adaptive and maladaptive processes. Psychological Bulletin, 110(1), 3.

Denham, S., \& Kochanoff, A. T. (2002). Parental contributions to preschoolers' understanding of emotion. Marriage \& Family Review, 34(3-4), 311-343.

Eisenberg, N., Cumberland, A., \& Spinrad, T. L. (1998). Parental socialization of emotion. Psychological Inquiry, 9(4), 241-273.

Eisenberg, N., Fabes, R. A., \& Murphy, B. C. (1996). Parents' reactions to children's negative emotions: Relations to children's social competence and comforting behavior. Child Development, 67(5), 2227-2247.

Fabes, R. A., Leonard, S. A., Kupanoff, K., \& Martin, C. L. (2001). Parental coping with children's negative emotions: Relations with children's emotional and social responding. Child Development, 72(3), 907-920.

Feldman, G. C., Joormann, J., \& Johnson, S. L. (2008). Responses to positive affect: A selfreport measure of rumination and dampening. Cognitive Therapy and Research, 32(4), 507.

Ford, B. Q., \& Mauss, I. B. (2014). The paradoxical effects of pursuing positive emotion: When and why wanting to feel happy backfires. In J. Gruber \& J. T. Moskowitz (Eds.), The Light and Dark Sides of Positive Emotion (pp. 363-381). New York, NY: Oxford 
University Press.

Fredrickson, B. L. \& Joiner, T. (2002). Positive emotions trigger upward spirals toward emotional well-being. Psychological Science, 13(2), 172-175.

Garrett-Peters, P., Mills-Koonce, R., Adkins, D., Vernon-Feagans, L., Cox, M., \& Family Life Project Key Investigators. (2008). Early environmental correlates of maternal emotion talk. Parenting: Science and Practice, 8(2), 117-152.

Garside, R. B., \& Klimes-Dougan, B. (2002). Socialization of discrete negative emotions: Gender differences and links with psychological distress. Sex Roles, 47(3), 115-128.

Gentzler, A. L., Morey, J. N., Palmer, C. A., \& Yi, C. Y. (2013). Young adolescents' responses to positive events: Associations with positive affect and adjustment. The Journal of Early Adolescence, 33(5), 663-683.

Gentzler, A. L., Palmer, C. A., Yi, C. Y., Root, A. E., \& Moran, K. M. (2018). Mothers' Ideal Positive Affect Predicts their Socialization of Children's Positive Affect. The Journal of genetic psychology, 179(2), 90-101.

Gentzler, A. L., Ramsey, M. A., \& Black, K. R. (2015). Mothers' attachment styles and their children's self-reported security, as related to maternal socialization of children's positive affect regulation. Attachment \& Human Development, 17(4), 376-398.

Gottman, J. \& Declaire, J. (1997). Raising an Emotionally Intelligent Child: The Heart of Parenting. New York, NY: Fireside.

Gottman, J. M., Katz, L. F., \& Hooven, C. (1996). Parental meta-emotion philosophy and the emotional life of families: Theoretical models and preliminary data. Journal of Family Psychology, 10(3), 243-268. 
Gruber, J., Mauss, I. B., \& Tamir, M. (2011). A dark side of happiness? How, when, and why happiness is not always good. Perspectives on Psychological Science, 6(3), 222-233.

Halberstadt, A. G., Dunsmore, J. C., Bryant, A. R., Parker, A. E., Beale, K. S., \& Thompson, J. A. (2013). Development and validation of the parents' beliefs about children's emotions questionnaire. Psychological Assessment, 25(4), 1195-1210.

Hooven, C., Gottman, J. M., \& Katz, L. F. (1995). Parental meta-emotion structure predicts family and child outcomes. Cognition \& Emotion, 9(2-3), 229-264.

Katz, L. F., \& Hunter, E. C. (2007). Maternal meta-emotion philosophy and adolescent depressive symptomatology. Social Development, 16(2), 343-360.

Katz, L. F., Shortt, J. W., Allen, N. B., Davis, B., Hunter, E., Leve, C., \& Sheeber, L. (2014). Parental emotion socialization in clinically depressed adolescents: Enhancing and dampening positive affect. Journal of Abnormal Child Psychology, 42(2), 205-215.

Klimes-Dougan, B., Brand, A. E., Zahn-Waxler, C., Usher, B., Hastings, P. D., Kendziora, K., \& Garside, R. B. (2007). Parental emotion socialization in adolescence: Differences in sex, age and problem status. Social Development, 16(2), 326-342.

Lagacé-Séguin, D. G., \& Coplan, R. J. (2005). Maternal emotional styles and child social adjustment: Assessment, correlates, outcomes and goodness of fit in early childhood. Social Development, 14(4), 613-636.

LeMoyne, T., \& Buchanan, T. (2011). Does "hovering" matter? Helicopter parenting and its effect on well-being. Sociological Spectrum, 31(4), 399-418.

Locke, J. Y., Campbell, M. A., \& Kavanagh, D. (2012). Can a parent do too much for their child? An examination by parenting professionals of the concept of overparenting. Journal of Psychologists and Counsellors in Schools, 22(2), 249-265. 
Maccoby, E. E., \& Martin, J. A. (1983). Socialization in the Context of the Family: Parent-Child Interaction. Journal of Child Psychology, 4, 1-101.

Mauss, I. B., Savino, N. S., Anderson, C. L., Weisbuch, M., Tamir, M., \& Laudenslager, M. L. (2012). The pursuit of happiness can be lonely. Emotion, 12(5), 908-912.

Mauss, I. B., Shallcross, A. J., Troy, A. S., John, O. P., Ferrer, E., Wilhelm, F. H., \& Gross, J. J. (2011). Don't hide your happiness! Positive emotion dissociation, social connectedness, and psychological functioning. Journal of Personality and Social Psychology, 100(4), 738.

Mirabile, S. P., Oertwig, D., \& Halberstadt, A. G. (2016). Parent emotion socialization and children's socioemotional adjustment: When is supportiveness no longer supportive?. Social Development. Advance online publication.

Moran, K. A., Root, A. E., Vizy, B. K., Wilson, T. K., \& Gentzler, A. L. (2018). Maternal socialization of children's positive affect regulation: Associations with children's savoring, dampening, and depressive symptoms. Social Development. Manuscript under review.

Morey, J. N., \& Gentzler, A. L. (2017). Parents' perceptions of and responses to children's emotions: Relations with meta-emotion philosophy and adult attachment. Parenting, 17(2), 73-103.

O'Neal, C. R., \& Magai, C. (2005). Do parents respond in different ways when children feel different emotions? The emotional context of parenting. Development and Psychopathology, 17(2), 467-487. 
Padilla-Walker, L. M., \& Nelson, L. J. (2012). Black hawk down?: Establishing helicopter parenting as a distinct construct from other forms of parental control during emerging adulthood. Journal of Adolescence, 35(5), 1177-1190.

Parker, A. E., Halberstadt, A. G., Dunsmore, J. C., Townley, G., Bryant, A., Thompson, J. A., \& Beale, K. S. (2012). Emotions are a window into one's heart: A qualitative analysis of parental beliefs about children's emotions across three ethnic groups. Monographs for the Society for Research in Child Development, 77(3), 1-136.

Paterson, A. D., Babb, K. A., Camodeca, A., Goodwin, J., Hakim-Larson, J., Voelker, S., \& Gragg, M. (2012). Emotion-Related Parenting Styles (ERPS): A short form for measuring parental meta-emotion philosophy. Early Education \& Development, 23(4), 583-602.

Saw, A., \& Okazaki, S. (2010). Family emotion socialization and affective distress in Asian American and White American college students. Asian American Journal of Psychology, 1(2), 81.

Schooler, J. W., Ariely, D., \& Loewenstein, G. (2003). The pursuit and assessment of happiness can be self-defeating. In J.C.I. Brocas (Ed.), The Psychology of Economic Decisions (Vol. Rationality and Well-Being, pp. 41-70). Oxford: Oxford University Press.

Segrin, C., Woszidlo, A., Givertz, M., Bauer, A., \& Taylor Murphy, M. (2012). The association between overparenting, parent-child communication, and entitlement and adaptive traits in adult children. Family Relations, 61(2), 237-252.

Sheldon, K. M., \& Houser-Marko, L. (2001). Self-concordance, goal attainment, and the pursuit of happiness: Can there be an upward spiral?. Journal of Personality and Social Psychology, 80(1), 152. 
Snyder, J., Stoolmiller, M., Wilson, M., \& Yamamoto, M. (2003). Child anger regulation, parental responses to children's anger displays, and early child antisocial behavior. Social Development, 12(3), 335-360.

Southam-Gerow, M. A., \& Kendall, P. C. (2002). Emotion regulation and understanding: Implications for child psychopathology and therapy. Clinical Psychology Review, 22(2), $189-222$.

Tsai, J. L., Knutson, B., \& Fung, H. H. (2006). Cultural variation in affect valuation. Journal of Personality and Social Psychology, 90(2), 288.

Yap, M. B., Allen, N. B., \& Ladouceur, C. D. (2008). Maternal socialization of positive affect: The impact of invalidation on adolescent emotion regulation and depressive symptomatology. Child Development, 79(5), 1415-1431.

Yi, C. Y., Gentzler, A. L., Ramsey, M. A., \& Root, A. E. (2016). Linking maternal socialization of positive emotions to children's behavioral problems: The moderating role of selfcontrol. Journal of Child and Family Studies, 25(5), 1550-1558. 
Table 1

Demographics for Study 1 and Study 2

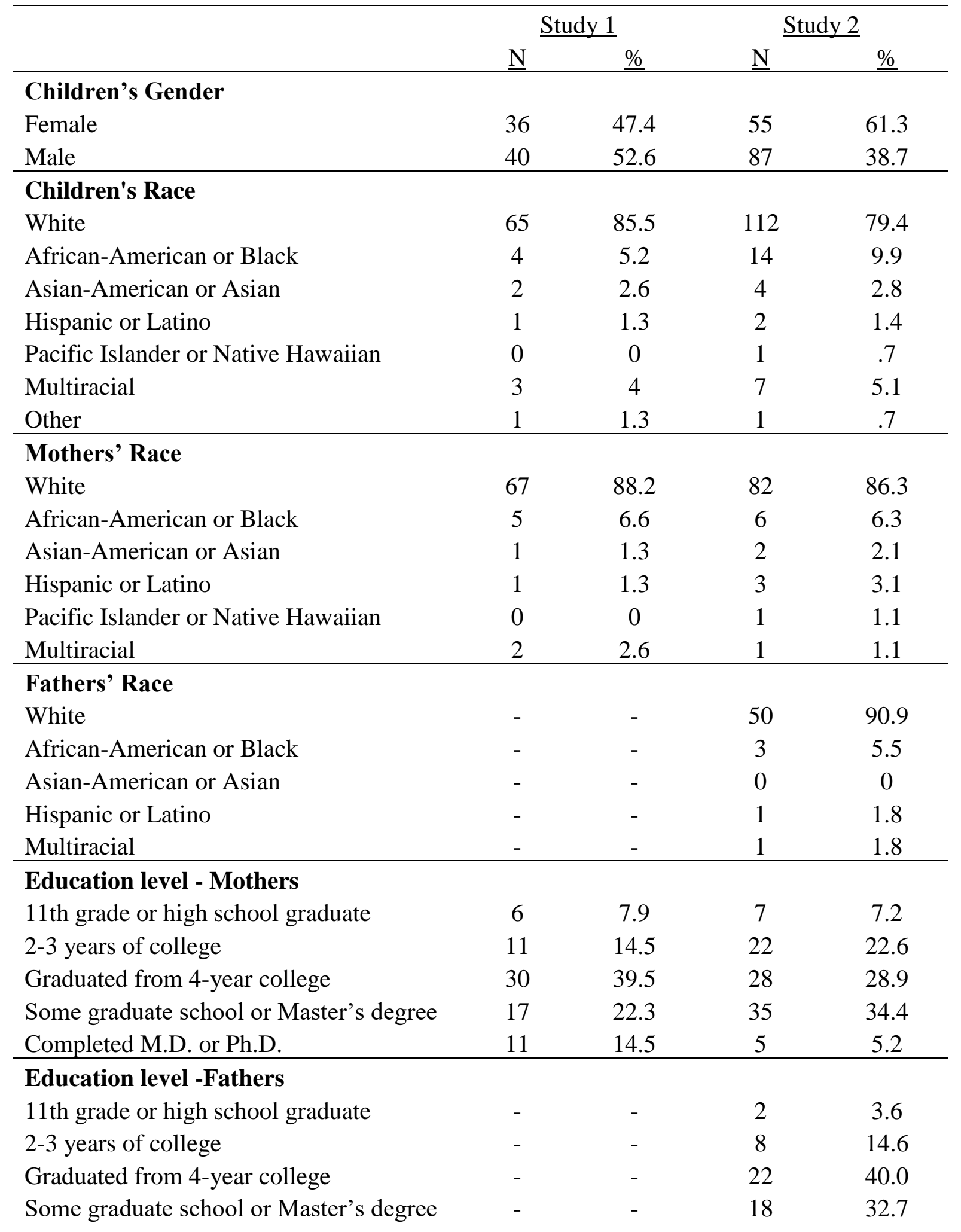




\begin{tabular}{lcccc} 
Completed M.D. or Ph.D. & - & - & 5 & 9.1 \\
\hline Household Income & & & & \\
$\$ 10,000-39,999$ & 11 & 14.4 & 4 & 4.3 \\
$\$ 40,000-79,999$ & 23 & 30.3 & 20 & 21.3 \\
$\$ 80,000-99,999$ & 12 & 15.8 & 12 & 12.8 \\
Over \$100,000-149,000 & 29 & 38.2 & 58 & 61.7 \\
\hline
\end{tabular}


Table 2

Study 1: Bivariate Correlation Statistics

\begin{tabular}{|c|c|}
\hline & Mothers' Valuing Children's Happiness \\
\hline \multicolumn{2}{|l|}{ Demographics } \\
\hline Children's Age & .09 \\
\hline Children's Gender & .03 \\
\hline Yearly Household Income & $-.28^{*}$ \\
\hline Highest Education Mother & $-.29^{* *}$ \\
\hline \multicolumn{2}{|l|}{ Mothers' Ideal PA for Children } \\
\hline High Arousal Positive & $.38^{* *}$ \\
\hline Moderate Arousal Positive & $.26^{*}$ \\
\hline Low Arousal Positive & .20 \\
\hline \multicolumn{2}{|l|}{ Children's Typical PA } \\
\hline High Arousal Positive & .15 \\
\hline Moderate Arousal Positive & -.19 \\
\hline Low Arousal Positive & -.16 \\
\hline \multicolumn{2}{|c|}{ Mothers' Socialization of Children's PA } \\
\hline Savoring & $.30^{* *}$ \\
\hline Dampening & .10 \\
\hline Savoring (Children’s Report) & .02 \\
\hline Dampening (Children’s Report) & .06 \\
\hline Explanation & .12 \\
\hline Encouragement & .02 \\
\hline Reprimand & .09 \\
\hline Discomfort & .01 \\
\hline
\end{tabular}


Table 3

Study 1: Hierarchical Regression Models Predicting Positive Affect (PA) Socialization from Mothers' Value of Children's Happiness and Covariates

\begin{tabular}{|c|c|c|c|c|c|c|}
\hline & & $\beta_{\text {in }}$ & $\beta_{\text {final }}$ & $\mathrm{R}^{2}$ & df & F Change \\
\hline \multicolumn{7}{|c|}{ Socialization of Savoring PA } \\
\hline \multirow[t]{4}{*}{ Step 1} & & & & .09 & 3,69 & 2.36 \\
\hline & Child Age & 15 & 11 & & & \\
\hline & Child Gender & .01 & -.01 & & & \\
\hline & Household Income & $-.29^{*}$ & -.22 & & & \\
\hline \multirow[t]{2}{*}{ Step 2} & & & & .14 & 1,68 & $3.99^{+}$ \\
\hline & Valuing Child Happiness & $.24^{+}$ & $.25^{*}$ & & & \\
\hline Step 3 & Child Actul $\Delta$ ffect & & & .29 & 1,67 & $14.07^{* * *}$ \\
\hline \multicolumn{7}{|c|}{ Socialization of Dampening PA } \\
\hline \multirow[t]{4}{*}{ Step 1} & & & & .02 & 3,69 & .42 \\
\hline & Child Age & .13 & .12 & & & \\
\hline & Child Gender & .04 & .03 & & & \\
\hline & Household Income & -.03 & -.01 & & & \\
\hline \multirow[t]{2}{*}{ Step 2} & & & & .02 & 1,68 & .44 \\
\hline & Valuing Child Happiness & .08 & .08 & & & \\
\hline \multirow[t]{2}{*}{ Step 3} & & & & .05 & 1,67 & 1.72 \\
\hline & Child Actual Affect & -.16 & -.16 & & & \\
\hline
\end{tabular}


Table 4

Study 1: Hierarchical Regression Models Predicting Positive Affect (PA) Socialization from Mothers' Value of Children's Happiness and Covariates

\begin{tabular}{|c|c|c|c|c|c|c|}
\hline & & $\beta$ in & $\beta$ final & $\mathrm{R}^{2}$ & df & F Change \\
\hline \multicolumn{7}{|l|}{ Explanation } \\
\hline \multirow{4}{*}{ Step 1} & & & & .04 & 3,69 & 1.02 \\
\hline & Child Age & -.21 & -.23 & & & \\
\hline & Child Gender & -.02 & -.03 & & & \\
\hline & Household Income & -.006 & .04 & & & \\
\hline \multirow[t]{2}{*}{ Step 2} & & & & .07 & 1,68 & 1.62 \\
\hline & Valuing Child Happiness & .16 & .16 & & & \\
\hline \multirow[t]{2}{*}{ Step 3} & & & & .10 & 1,67 & 2.91 \\
\hline & Child Actual Affect & .20 & 20 & & & \\
\hline \multirow{5}{*}{$\frac{\text { Encouragement }}{\text { Step } 1}$} & & & & & & \\
\hline & & & & .04 & 3,69 & .98 \\
\hline & Child Age & .02 & .02 & & & \\
\hline & Child Gender & .19 & .19 & & & \\
\hline & Household Income & -.08 & -.09 & & & \\
\hline \multirow[t]{2}{*}{ Step 2} & & & & .04 & 1,68 & .07 \\
\hline & Valuing Child Happiness & -.03 & -.03 & & & \\
\hline Step 3 & Child Actual Affect & $25^{*}$ & $25^{*}$ & .10 & 1,67 & $4.26^{*}$ \\
\hline \multicolumn{7}{|l|}{ Reprimand } \\
\hline \multirow[t]{4}{*}{ Step 1} & & & & .01 & 3,69 & .29 \\
\hline & Child Age & -.05 & -.07 & & & \\
\hline & Child Gender & -.02 & -.04 & & & \\
\hline & Household Income & .11 & .15 & & & \\
\hline \multirow[t]{2}{*}{ Step 2} & & & & .04 & 1,68 & 1.60 \\
\hline & Valuing Child Happiness & .16 & .15 & & & \\
\hline \multirow{2}{*}{ Step 3} & & & & .06 & 1,67 & 1.97 \\
\hline & Child Actual Affect & -.17 & -.17 & & & \\
\hline \multicolumn{7}{|l|}{ Discomfort } \\
\hline \multirow[t]{4}{*}{ Step 1} & & & & .06 & 3,69 & 1.48 \\
\hline & Child Age & .18 & .17 & & & \\
\hline & Child Gender & -.06 & -.06 & & & \\
\hline & Household Income & .14 & .15 & & & \\
\hline \multirow[t]{2}{*}{ Step 2} & & & & .06 & 1,68 & .07 \\
\hline & Valuing Child Happiness & .03 & .03 & & & \\
\hline Step 3 & Child Actual Affect & $-.24^{*}$ & $-.24^{*}$ & .12 & 1,67 & $4.19^{*}$ \\
\hline
\end{tabular}

Note. Gender coded $2=$ male, $1=$ female. ${ }^{*} p<.05$. 
Table 5

Bivariate Correlation Statistics for Study 2

\begin{tabular}{|c|c|c|c|c|}
\hline & $\begin{array}{c}\text { Mothers' } \\
\text { Value of } \\
\text { Adolescent's } \\
\text { Happiness }\end{array}$ & $\begin{array}{c}\text { Fathers' } \\
\text { Value of } \\
\text { Adolescent's } \\
\text { Happiness }\end{array}$ & $\begin{array}{c}\text { Mothers' } \\
\text { Value of } \\
\text { Adolescent's } \\
\text { Happiness } \\
\text { (Teen } \\
\text { Report) }\end{array}$ & $\begin{array}{c}\text { Fathers' } \\
\text { Value of } \\
\text { Adolescent's } \\
\text { Happiness } \\
\text { (Teen } \\
\text { Report) }\end{array}$ \\
\hline \multicolumn{5}{|l|}{ Demographics } \\
\hline Adolescents' Age & -.09 & .05 & .04 & .08 \\
\hline Adolescents' Gender & .16 & -.21 & -.09 & -.01 \\
\hline Household Income & .03 & -.15 & $.26^{*}$ & .09 \\
\hline Education Mother & -.05 & -.16 & -.06 & -.02 \\
\hline Education Father & .10 & -.08 & .12 & .21 \\
\hline \multicolumn{5}{|l|}{ Adolescents' Ideal Affect } \\
\hline High Arousal Positive & $.26^{*}$ & .20 & -.03 & -.03 \\
\hline Moderate Arousal Positive & $.23^{*}$ & .06 & .08 & -.18 \\
\hline Low Arousal Positive & .06 & .18 & .04 & .06 \\
\hline \multicolumn{5}{|l|}{ Adolescents' Actual Affect } \\
\hline High Arousal Positive & .18 & $.27^{*}$ & .01 & .01 \\
\hline Moderate Arousal Positive & -.07 & .10 & -.06 & .11 \\
\hline Low Arousal Positive & -.01 & .25 & -.04 & .01 \\
\hline \multicolumn{5}{|l|}{ NA Socialization } \\
\hline Accept Adolescent's NA & .07 & $-.31^{+}$ & -.02 & -.20 \\
\hline Reject Adolescent's NA & $.37^{* *}$ & .17 & .15 & .27 \\
\hline Coach Adolescent's NA & .06 & .16 & -.11 & -.11 \\
\hline Uncertainty with & & & & \\
\hline Adolescent's NA & $.27^{* *}$ & .01 & .01 & .03 \\
\hline \multicolumn{5}{|l|}{ Parenting } \\
\hline Helicopter & .09 & .22 & $.33^{* *}$ & $.40^{* *}$ \\
\hline Indulgence & $.20^{*}$ & .16 & $.28^{* *}$ & $.40^{* *}$ \\
\hline
\end{tabular}

Note. Child reported on socialization and parenting practices corresponding to the specific parent. NA $=$ negative affect. Gender coded $0=$ male, $1=$ female. ${ }^{+} p=.05,{ }^{*} p<.05 .{ }^{* *} p<.01$. 
Table 6.

Study 2: Hierarchical Regression Models Predicting Negative Affect (NA) Socialization from Mother-reported Mothers' Value of Adolescent's Happiness

\begin{tabular}{|c|c|c|c|c|c|c|}
\hline & & $\beta_{\text {in }}$ & $\beta_{\text {final }}$ & $\mathrm{R}^{2}$ & df & F Change \\
\hline \multicolumn{7}{|l|}{ Accept NA } \\
\hline \multirow[t]{4}{*}{ Step 1} & & & & .04 & 3,79 & 1.15 \\
\hline & Child Age & -.04 & -.04 & & & \\
\hline & Child Gender & .19 & .19 & & & \\
\hline & Household Income & .04 & .04 & & & \\
\hline \multirow[t]{2}{*}{ Step 2} & & & & .05 & 1,78 & .27 \\
\hline & Valuing Child Happiness & .06 & .06 & & & \\
\hline \multirow[t]{2}{*}{ Step 3} & & & & .05 & 1,77 & .46 \\
\hline & Child Actual Affect & -.08 & -.08 & & & \\
\hline \multirow{5}{*}{$\frac{\text { Reject NA }}{\text { Step } 1}$} & & & & & & \\
\hline & & & & .01 & 3,79 & .27 \\
\hline & Child Age & .08 & .13 & & & \\
\hline & Child Gender & -.04 & -.06 & & & \\
\hline & Household Income & .01 & -.01 & & & \\
\hline \multirow[t]{2}{*}{ Step 2} & & & & .13 & 1,78 & $10.37^{* *}$ \\
\hline & Valuing Child Happiness & $.35^{* *}$ & $.45^{* *}$ & & & \\
\hline Step 3 & Child $\Delta$ cturl $\Delta$ ffect & 07 & & .13 & 1,77 & 46 \\
\hline \multirow{5}{*}{$\frac{\text { Coach NA }}{\text { Step } 1}$} & 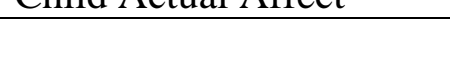 & & & & & \\
\hline & & & & .09 & 3,79 & 2.54 \\
\hline & Child Age & .05 & .06 & & & \\
\hline & Child Gender & -.16 & -.17 & & & \\
\hline & Household Income & -.26 & -.27 & & & \\
\hline \multirow[t]{2}{*}{ Step 2} & & & & .10 & 1,78 & .84 \\
\hline & Valuing Child Happiness & .10 & .09 & & & \\
\hline \multirow{2}{*}{ Step 3} & & & & .11 & 1,77 & 1.11 \\
\hline & Child Actual Affect & .12 & .12 & & & \\
\hline \multirow{2}{*}{\multicolumn{4}{|c|}{$\begin{array}{l}\text { Uncertainty/Ineffective NA Socialization } \\
\text { Step 1 }\end{array}$}} & & & \\
\hline & & & & .07 & 3,79 & 1.97 \\
\hline & Child Age & .12 & .15 & & & \\
\hline & Child Gender & .05 & .03 & & & \\
\hline \multirow{3}{*}{ Step 2} & Household Income & $.22^{*}$ & .21 & & & \\
\hline & & & & .13 & 1,78 & $5.62^{*}$ \\
\hline & Valuing Child Happiness & $.25^{*}$ & $.27^{* *}$ & & & \\
\hline Step 3 & Child Actual Affect & $-.34^{* *}$ & $-.34^{* *}$ & .24 & 1,77 & $10.74^{* *}$ \\
\hline
\end{tabular}


Table 7

Study 2: Hierarchical Regression Models Predicting Negative Affect (NA) Socialization from Father-reported Fathers' Value of Adolescent's Happiness

\begin{tabular}{|c|c|c|c|c|c|c|}
\hline & & $\beta_{\text {in }}$ & $\beta_{\text {final }}$ & $\mathrm{R}^{2}$ & $\mathrm{df}$ & F Change \\
\hline \multicolumn{7}{|l|}{ Accept NA } \\
\hline \multirow[t]{4}{*}{ Step 1} & & & & .03 & 3,44 & .43 \\
\hline & Child Age & -.02 & -.002 & & & \\
\hline & Child Gender & -.06 & -.11 & & & \\
\hline & Household Income & .15 & .12 & & & \\
\hline \multirow[t]{2}{*}{ Step 2} & & & & .05 & 1,43 & 1.12 \\
\hline & Valuing Child Happiness & -.17 & -.20 & & & \\
\hline \multirow[t]{2}{*}{ Step 3} & & & & .06 & 1,42 & .24 \\
\hline & Child Actual Affect & .09 & .09 & & & \\
\hline \multicolumn{7}{|l|}{ Reject NA } \\
\hline \multirow[t]{4}{*}{ Step 1} & & & & .05 & 3,44 & .74 \\
\hline & Child Age & -.05 & -.08 & & & \\
\hline & Child Gender & -.20 & -.10 & & & \\
\hline & Household Income & .05 & .12 & & & \\
\hline \multirow[t]{2}{*}{ Step 2} & & & & .15 & 1,43 & $5.27^{*}$ \\
\hline & Valuing Child Happiness & $.35^{*}$ & $.32^{+}$ & & & \\
\hline \multirow[t]{2}{*}{ Step 3} & & & & .16 & 1,42 & .24 \\
\hline & Child Actual Affect & .08 & .08 & & & \\
\hline \multicolumn{7}{|l|}{ Coach NA } \\
\hline \multirow[t]{4}{*}{ Step 1} & & & & .02 & 3,44 & .35 \\
\hline & Child Age & -.05 & -.06 & & & \\
\hline & Child Gender & -.14 & -.09 & & & \\
\hline & Household Income & -.06 & -.03 & & & \\
\hline \multirow[t]{2}{*}{ Step 2} & & & & .04 & 1,43 & .701 \\
\hline & Valuing Child Happiness & .13 & -.01 & & & \\
\hline \multirow[t]{2}{*}{ Step 3} & & & & .19 & 1,42 & $7.53^{* *}$ \\
\hline & Child Actual Affect & $.46^{* *}$ & $.46^{* *}$ & & & \\
\hline \multicolumn{7}{|c|}{ Uncertainty/Ineffective NA Socialization } \\
\hline \multirow[t]{4}{*}{ Step 1} & & & & .06 & 3,44 & 1.00 \\
\hline & Child Age & .19 & .16 & & & \\
\hline & Child Gender & -.001 & .08 & & & \\
\hline & Household Income & .15 & .20 & & & \\
\hline \multirow[t]{2}{*}{ Step 2} & & & & .12 & 1,43 & 2.86 \\
\hline & Valuing Child Happiness & .26 & $.37^{*}$ & & & \\
\hline \multirow[t]{2}{*}{ Step 3} & & & & .20 & 1,42 & $4.11^{*}$ \\
\hline & Child Actual Affect & $-.34^{*}$ & $-.34^{*}$ & & & \\
\hline
\end{tabular}


Table 8

Study 2: Hierarchical Regression Models Predicting Parenting Behaviors from Adolescentreported Parents' Value of Adolescent's Happiness

\begin{tabular}{|c|c|c|c|c|c|c|}
\hline & & $\beta_{\text {in }}$ & $\beta_{\text {final }}$ & $\mathrm{R}^{2}$ & df & F Change \\
\hline \multicolumn{7}{|c|}{ Mother Helicopter Parenting } \\
\hline \multirow[t]{4}{*}{ Step 1} & & & & .07 & 3,75 & 1.85 \\
\hline & Child Age & $-.25^{*}$ & $-.25^{*}$ & & & \\
\hline & Child Gender & .04 & .04 & & & \\
\hline & Household Income & .07 & .07 & & & \\
\hline \multirow[t]{2}{*}{ Step 2} & & & & .07 & 1,74 & .22 \\
\hline & Valuing Child Happiness & .05 & .05 & & & \\
\hline \multirow[t]{2}{*}{ Step 3} & & & & .09 & 1,73 & 1.35 \\
\hline & Child Actual Affect & .13 & .13 & & & \\
\hline \multicolumn{7}{|c|}{ Father Helicopter Parenting } \\
\hline \multirow[t]{4}{*}{ Step 1} & & & & .05 & 3,42 & .72 \\
\hline & Child Age & -.11 & -.15 & & & \\
\hline & Child Gender & .07 & .17 & & & \\
\hline & Household Income & .20 & .26 & & & \\
\hline \multirow[t]{2}{*}{ Step 2} & & & & .13 & 1,41 & $3.99^{+}$ \\
\hline & Valuing Child Happiness & $.31^{+}$ & .29 & & & \\
\hline \multirow[t]{2}{*}{ Step 3} & & & & .14 & 1,40 & .10 \\
\hline & Child Actual Affect & .06 & .06 & & & \\
\hline \multicolumn{7}{|c|}{ Mother Indulgent Parenting } \\
\hline \multirow[t]{4}{*}{ Step 1} & & & & .05 & 3,74 & 1.18 \\
\hline & Child Age & .05 & .08 & & & \\
\hline & Child Gender & .14 & .13 & & & \\
\hline & Household Income & .17 & 16 & & & \\
\hline \multirow[t]{2}{*}{ Step 2} & & & & .08 & 1,73 & 3.09 \\
\hline & Valuing Child Happiness & .20 & .18 & & & \\
\hline \multirow[t]{2}{*}{ Step 3} & & & & .18 & 1,72 & $8.60^{* *}$ \\
\hline & Child Actual Affect & $.32^{* *}$ & $.32^{* *}$ & & & \\
\hline \multicolumn{7}{|c|}{ Father Indulgent Parenting } \\
\hline \multirow[t]{4}{*}{ Step 1} & & & & .04 & 3,42 & .62 \\
\hline & Child Age & .02 & -.005 & & & \\
\hline & Child Gender & .12 & .19 & & & \\
\hline & Household Income & .18 & .23 & & & \\
\hline \multirow[t]{2}{*}{ Step 2} & & & & .09 & 1,41 & 2.28 \\
\hline & Valuing Child Happiness & .24 & .21 & & & \\
\hline \multirow[t]{2}{*}{ Step 3} & & & & .10 & 1,40 & .27 \\
\hline & Child Actual Affect & .09 & .09 & & & \\
\hline
\end{tabular}

Note. Gender coded $0=$ male, $1=$ female. ${ }^{+} p=.05 .{ }^{*} p<.05 .{ }^{* *} p<.01$. 


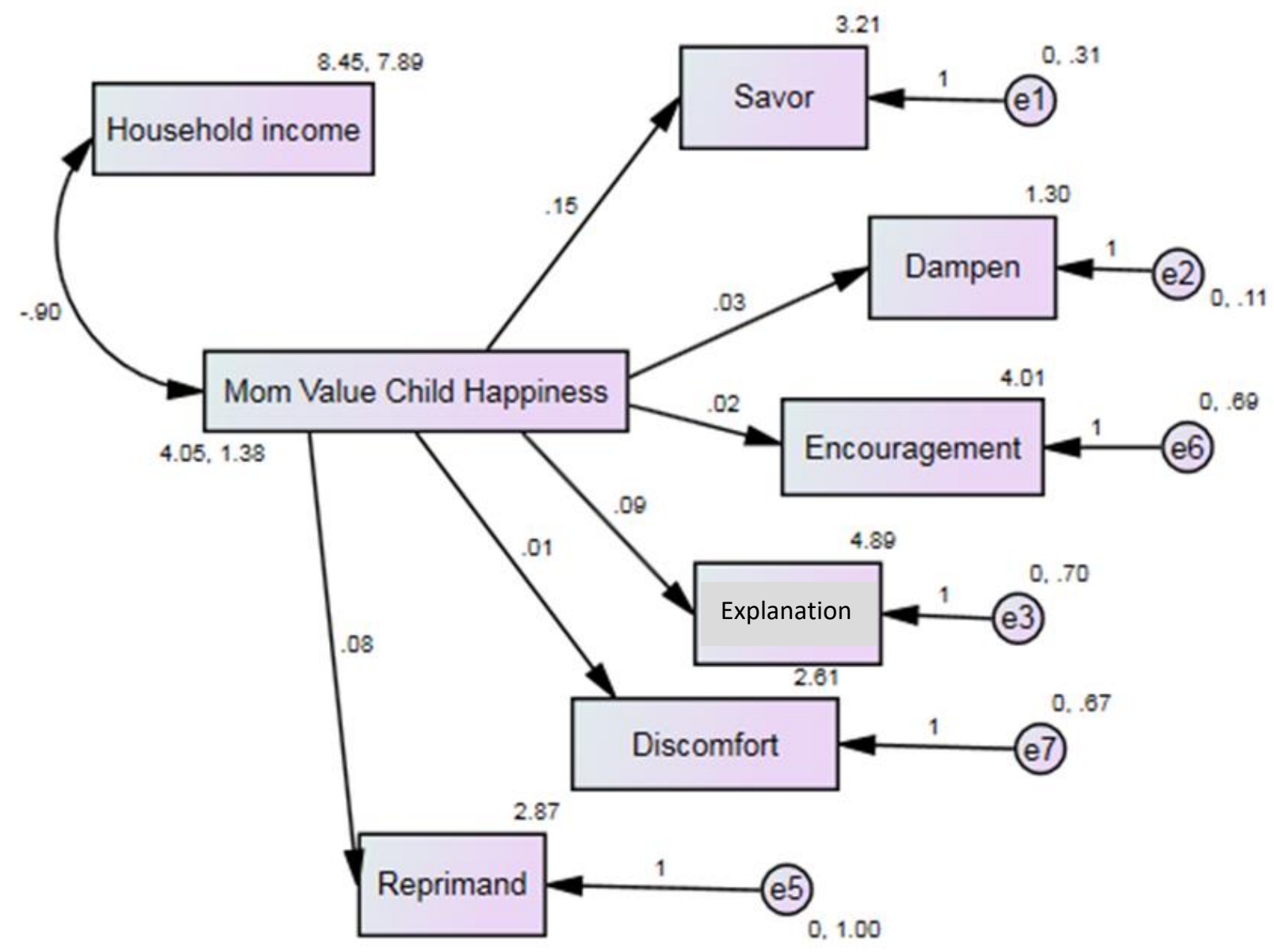

Figure 1a. Proposed model: Mothers' value of their child's happiness predicting use of positive emotion regulation behaviors with household income controlled. 


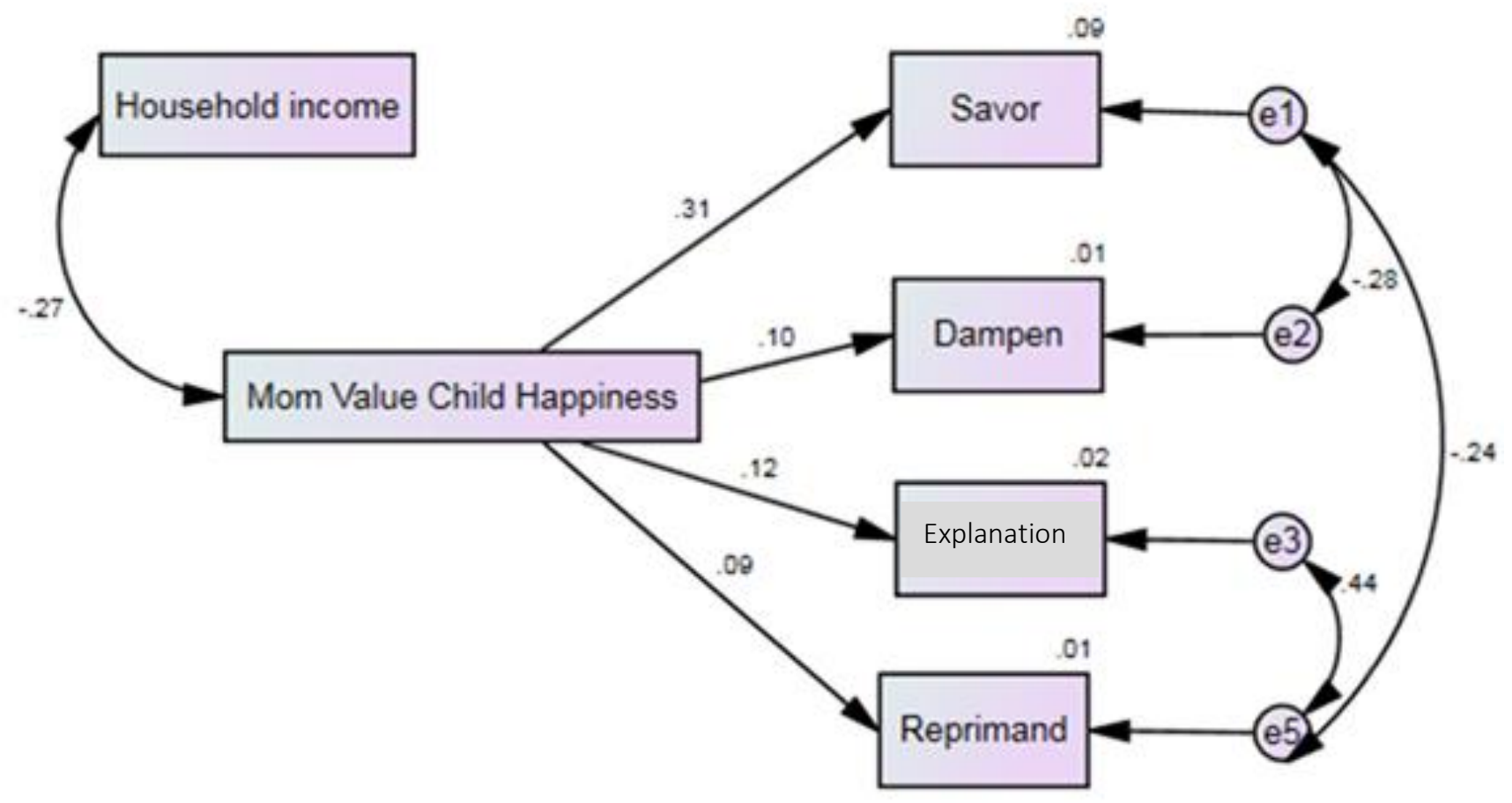

Figure $1 b$. Trimmed model. Standardized estimates for the associations between mothers' value of their child's happiness and positive emotion socialization behaviors. 


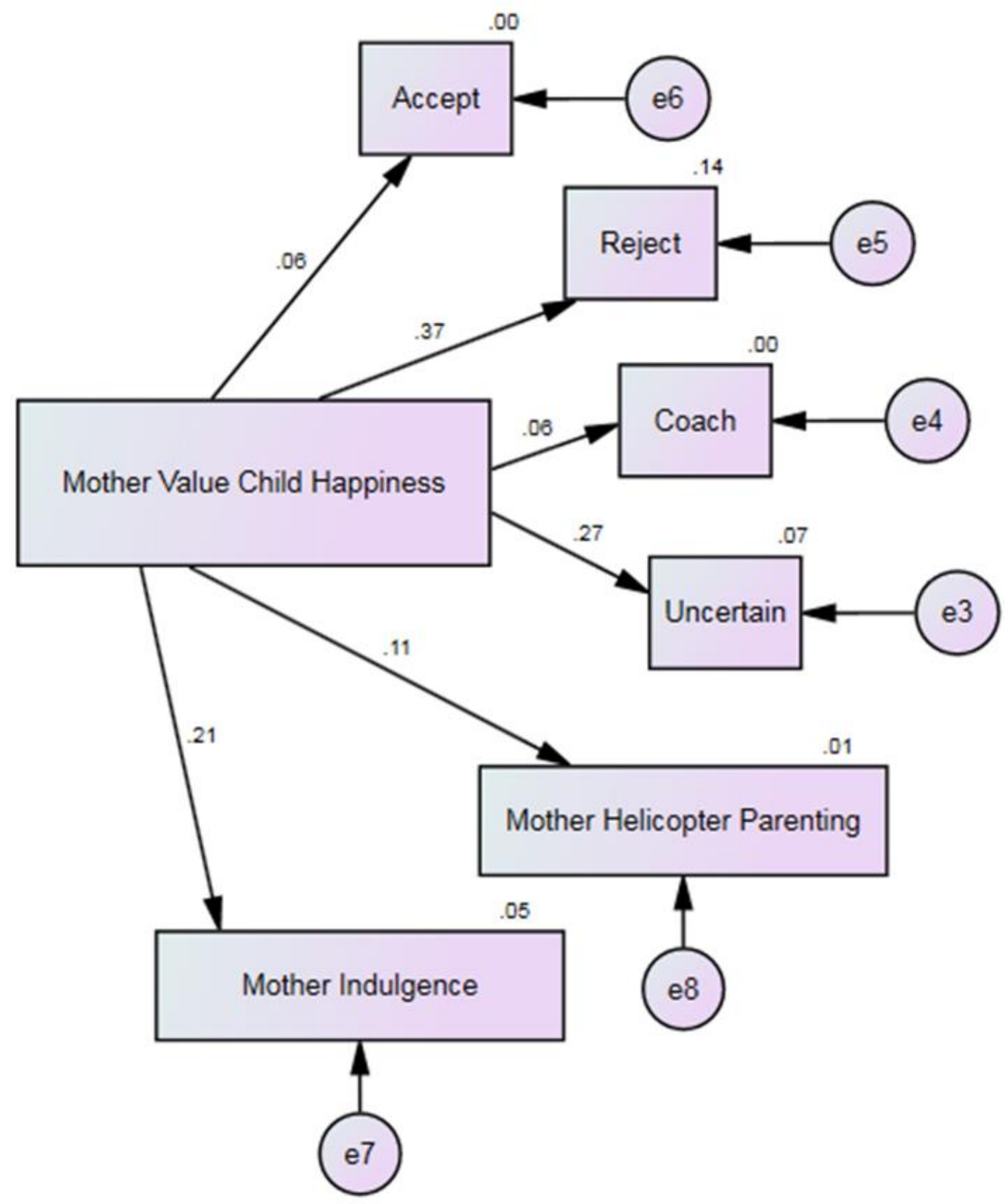

Figure 2a. Trimmed model. Standardized estimates for the associations between mothers' value of their child's happiness and positive emotion socialization behaviors. 


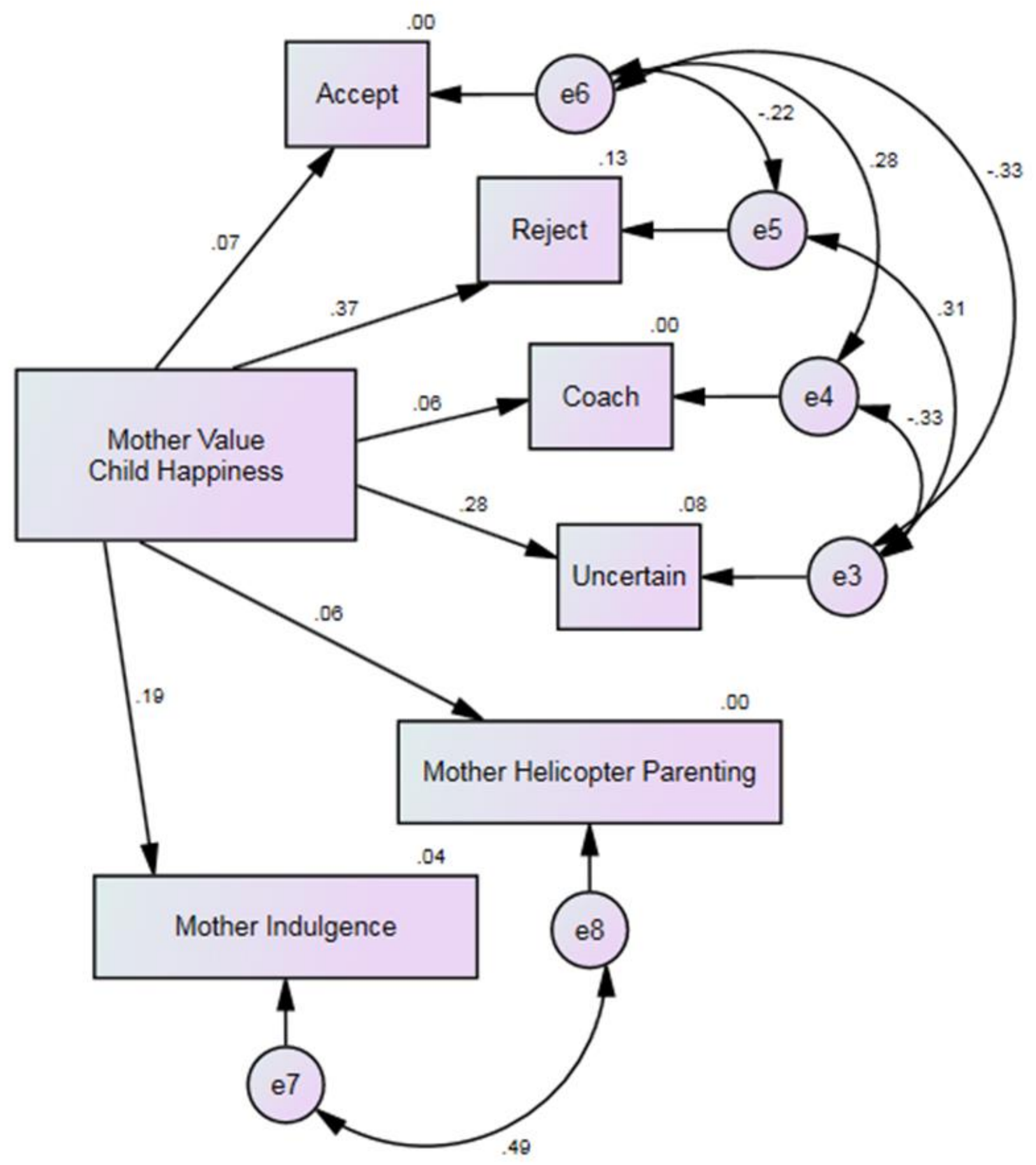

Figure $2 b$. Final model: Standardized estimates for the associations between mothers' value of their child's happiness, negative emotion socialization beliefs and parenting behaviors. 


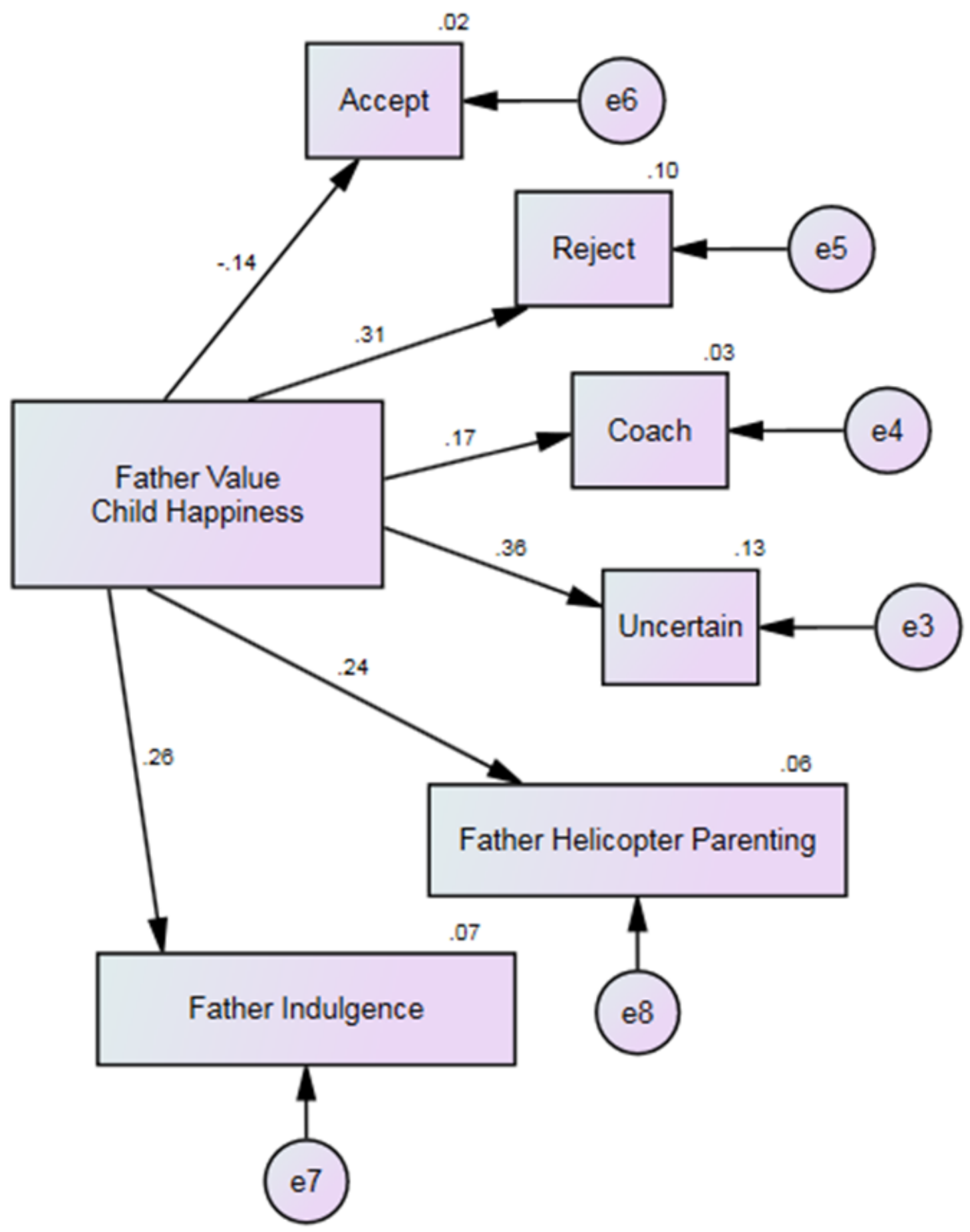

Figure 3a. Proposed model: Fathers' value of their child's happiness predicting negative emotion socialization beliefs and parenting behaviors. 


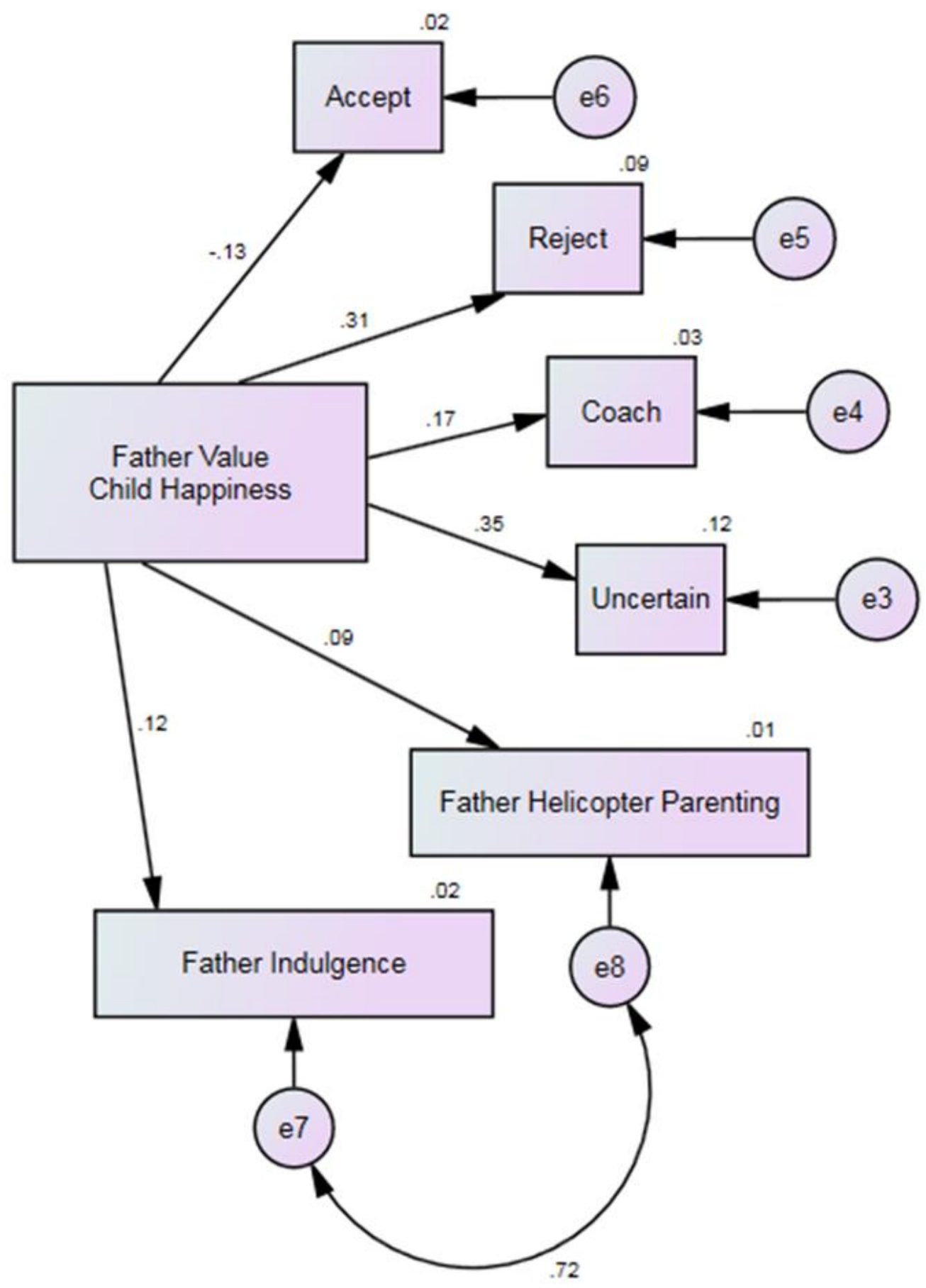

Figure 3b. Final model: Standardized estimates for the associations between fathers' value of their child's happiness, negative emotion socialization beliefs and parenting behaviors. 